\title{
Archipel du Kvarner (Croatie)
}

Prospection-inventaire des sites ecclésiaux et monastiques : campagne 2014

Morana Čaušević-Bully et Sébastien Bully

\section{(2) OpenEdition}

\section{Journals}

Édition électronique

URL : http://journals.openedition.org/cefr/1405

DOI : $10.4000 /$ cefr. 1405

ISSN : 2282-5703

Éditeur

École française de Rome

Référence électronique

Morana Čaušević-Bully et Sébastien Bully, « Archipel du Kvarner (Croatie) », Chronique des activités archéologiques de l'École française de Rome [En ligne], Balkans, mis en ligne le 10 juillet 2015, consulté le 12 septembre 2019. URL : http://journals.openedition.org/cefr/1405; DOI : 10.4000/cefr.1405

Ce document a été généré automatiquement le 12 septembre 2019.

(c) École française de Rome 


\section{Archipel du Kvarner (Croatie)}

Prospection-inventaire des sites ecclésiaux et monastiques : campagne

2014

Morana Čaušević-Bully et Sébastien Bully

\section{NOTE DE L'AUTEUR}

Avec la collaboration de Ivan Valent

1 Parmi les six sites retenus au terme de la première campagne menée en $2010^{1}$, nous sommes à nouveau intervenus en 2014 sur trois d'entre eux : les complexes de MirineFulfinum (île de Krk), de Martinšćica (île de Cres), et le site de l'îlot de Lukovac (île de Rab).

La campagne s'est déroulée en trois temps : du 27 avril au 10 mai à Mirine, du 30 juin au 12 juillet à Martinšćica, et du 20 au 25 octobre à Lukovac ${ }^{2}$. L'ensemble des interventions participe à l'évaluation du potentiel archéologique enfoui ou en élévation des sites afin d'en préciser la datation et la nature potentiellement monastique. Rappelons que le programme de prospection-inventaire des sites ecclésiaux insulaires est structuré autour de trois axes majeurs ${ }^{3}$ :

- Identification des sites monastiques potentiels à partir des sources écrites, des données archéologiques, architecturales et topographiques ;

- Conditions et modalités de l'installation et de la diffusion du monachisme insulaire dans le Kvarner, entre le $v^{e}$ et le $\mathrm{xl}^{\mathrm{e}}$ siècle : occupation du sol et voies maritimes, construction de l'espace;

- Topographie monastique et architecture cultuelle: héritages et influences, cénobitisme et érémitisme. 


\section{Fulfinum - Mirine (Omišalj) baie de Sepen, île de Krk (troisième campagne) : fouille des mausolées}

2 Les trois dernières campagnes ont porté sur la préparation à la fouille et sur la fouille de deux constructions situées entre le forum de Fulfinum et l'église paléochrétienne de Mirine (fig. 1).

Fig. 1 - Mirine-Fulfinum, vue générale du secteur des mausolées.

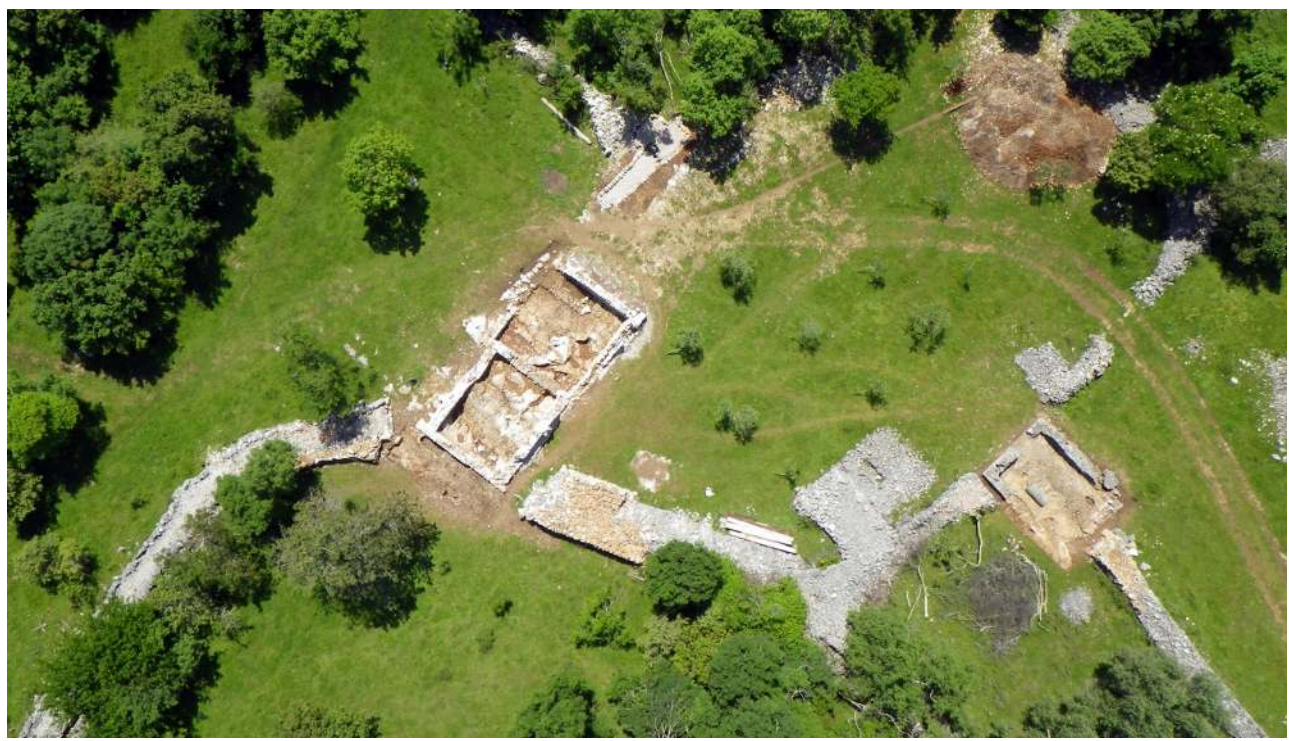

M. Vuković, 2014.

Le bâtiment le plus au sud (Bât. II.1), enfoui sous un tas d'épierrement, avait été repéré depuis plusieurs années et interprété alors comme une potentielle construction en lien avec le monastère médiéval Saint-Nicolas en raison de sa situation et de son ampleur présumée. Sa fouille, entreprise au mois d'avril 2013 et achevée au mois de mai 2014, avait donc pour objectif d'en définir le plan et la fonction. Seule la moitié ouest du bâtiment avait été fouillée lors de la première campagne, mais les données recueillies indiquaient d'ores et déjà qu'il s'agissait en fait d'un mausolée. Celui-ci prend place au sein d'une nécropole de l'Antiquité tardive qui se développe à l'est de la basilique paléochrétienne, connue depuis des recherches effectuées par une équipe de l'UNESCO et du Centre de Préservation des Monuments de Rijeka dans les années 1990. Les recherches archéologiques avaient révélé une série de tombes familiales, en amphore, maçonnées, ou en pleine terre, ainsi qu'un petit bâtiment de plan rectangulaire interprété comme une memoria (Bât. II.3). Inachevée et non documentée lors de la première campagne des années 1990, la dite memoria a donc fait l'objet cette année d'une révision de fouille qui a également pris en compte son environnement proche.

\section{Principaux résultats}

\section{Mausolée II. 1}

3 Le mausolée est de plan rectangulaire de 4,6 × $6 \mathrm{~m}$ hors-œuvre dans une première phase (Bât. II.1A) (fig. 2). 
Fig. 2 - Mirine-Fulfinum, relevés en plan et en élévation du mausolée II.1.

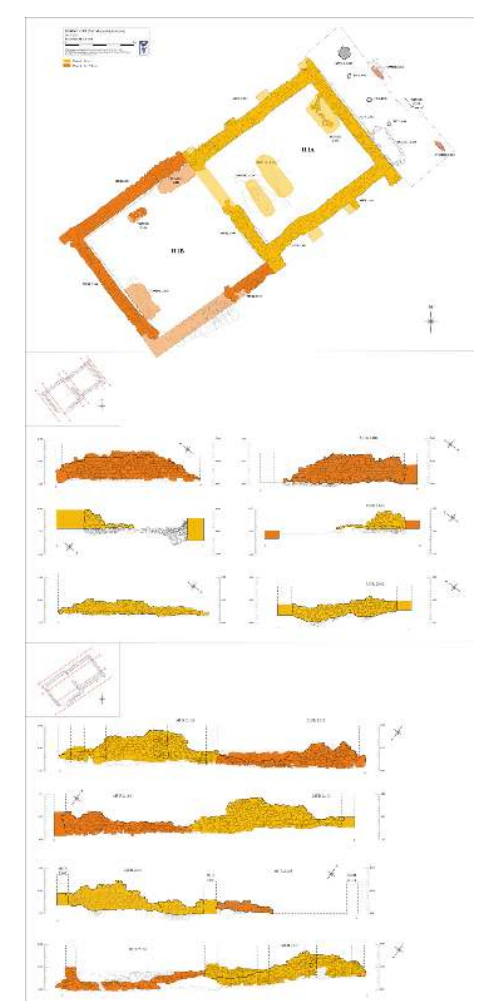

D’après Société Kaducej et D. Vuillermoz.

Il suit une orientation respectueuse de la trame urbaine et périurbaine du site (nord-est/ sud-ouest). Les maçonneries en opus incertum, irrégulièrement conservées jusqu'à $1,45 \mathrm{~m}$ maximum en élévation, mesurent 0,68 $\mathrm{m}$ d'épaisseur; les parements extérieurs sont scandés par une série de contreforts que l'on restitue au nombre de quatre par murs gouttereaux en fonction des traces d'arrachements et du rythme (fig. 2). La massivité des contreforts $( \pm 0,68 \times 0,40 \mathrm{~m})$ par rapport à la taille du bâtiment, indique qu'il s'agissait d'un espace voûté. Malgré l'aspect des maçonneries construites en opus incertum, les murs de cette première phase montrent un souci de régularité des assises. Les petits moellons sont abondamment liés au mortier. Dans leur mise en œuvre, les maçonneries s'apparentent fortement à celles de la grande église du $\mathrm{V}^{\mathrm{e}} \mathrm{s}$. de Mirine (fig. 3). 
Fig. 3 - Mirine-Fulfinum, vue générale du mausolée II.1 au terme de la fouille.

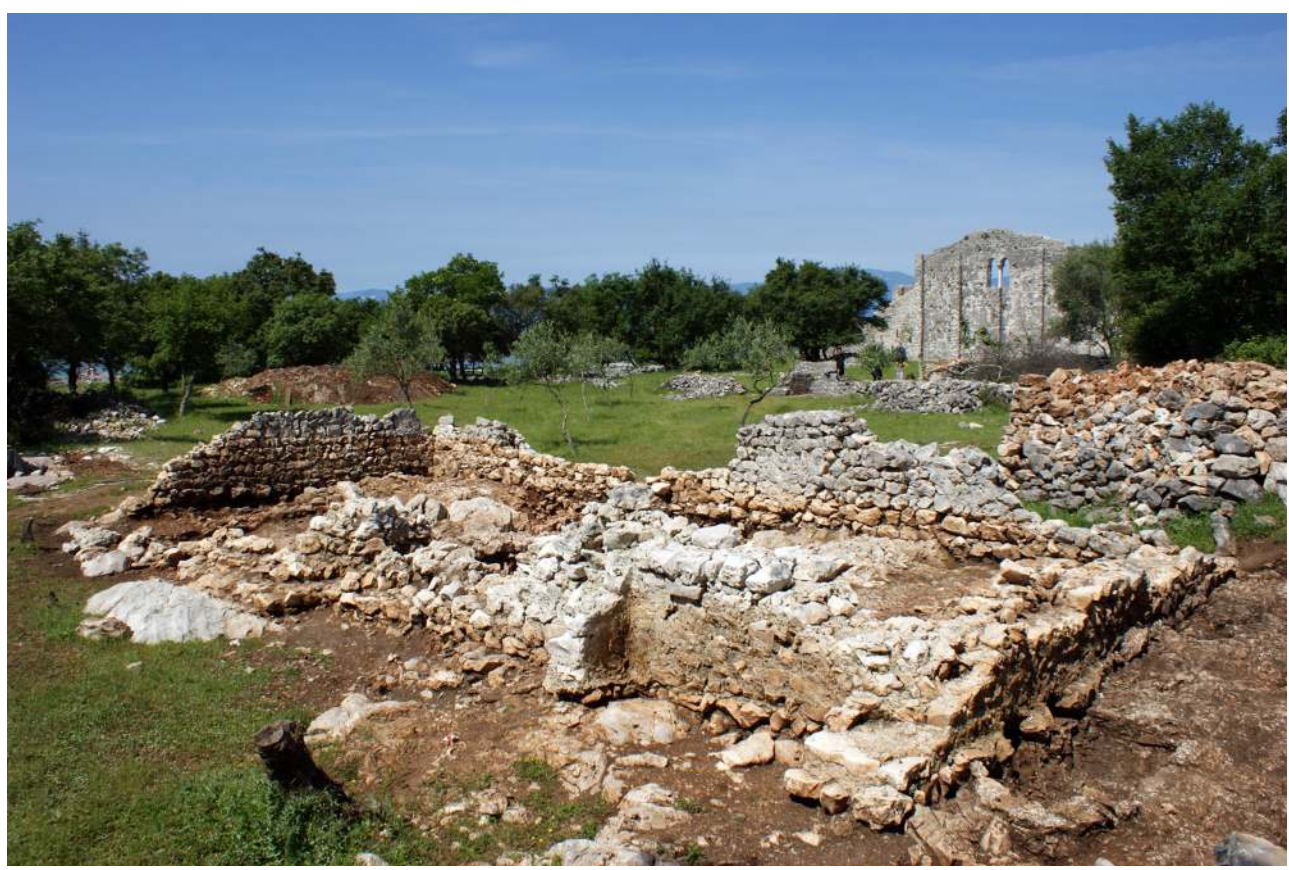

Complexe paléochrétien de Mirine en arrière-plan.

E. Balić, 2014.

Dans une seconde phase (II.1B), le mausolée est agrandi par l'adjonction en façade sud d'une nouvelle salle, légèrement plus large, de plan quadrangulaire de 5,5 x 5,6 m horsœuvre (fig. 2). Les maçonneries en opus incertum de la seconde phase sont identiques en largeur, mais ne comportent pas de contreforts; l'espace devait être couvert par une simple charpente. L'opus incertum employé dans les maçonneries de cette phase montre des irrégularités plus importantes (fig. 2). Les blocs de dimensions très variées sont disposés en assises irrégulières, tandis que l'usage de mortier est grandement diminué.

5 La fouille exhaustive de l'espace interne du mausolée primitif a révélé quatre tombes semi-rupestres, qui ont accueilli cinq individus. Une première (2.111), en position centrale, orientée nord-ouest - sud-est, contenait probablement l'inhumation d'une femme immature (IND 2) (fig. 4). 
Fig. 4 - Mirine-Fulfinum, tombe 2.111 dans le mausolée II.1A.

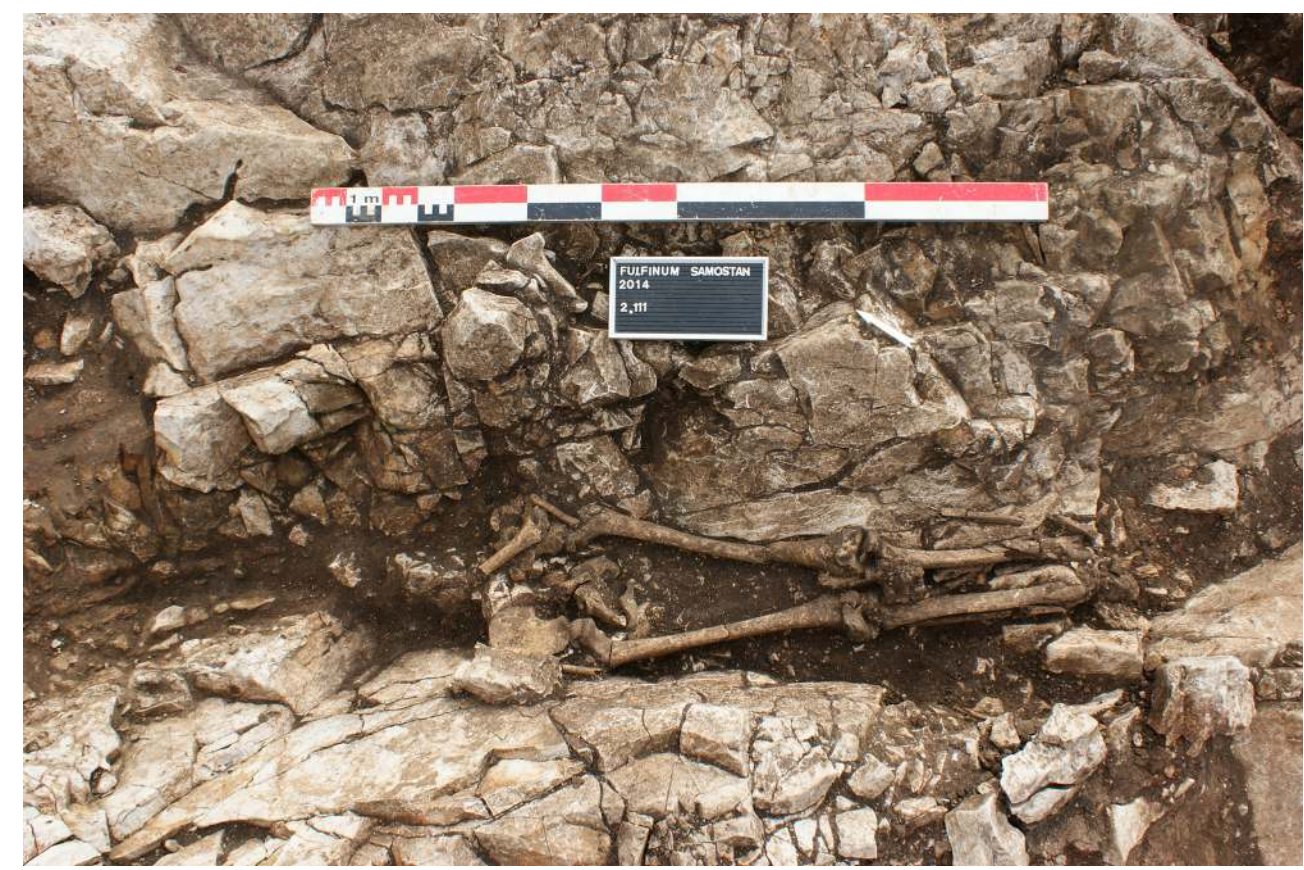

E. Balić, 2014.

Le comblement (2.1011) de la tombe a livré de la céramique, du verre, ainsi que des objets métalliques, dont un hameçon de pêche en bronze. Quelques ossements humains d'une inhumation primitive, probablement perturbée par l'individu 2, ont été également repérés dans le comblement de sa tombe. La seconde tombe (2.109 - fouillé en 2013), située le long du mur nord, contenait également l'inhumation d'une femme immature. Elle était cette fois-ci dotée d'une parure composée d'un bracelet en bronze sur son bras droit, de deux bracelets au bras gauche - un en fer et l'autre en bronze. Un couteau qui devait être initialement accroché à la ceinture a été découvert entre les jambes. Cette tombe est datée des premières décennies $d u V^{e} s$. par radiocarbone $e^{4}$. Une troisième tombe (2.120) accueillant l'inhumation d'une personne adulte (IND 9) est disposée parallèlement à la tombe 2.111 ; sa fouille n'a révélé aucune parure ni mobilier.

6 L'augmentum sud (II.1B) accueillait trois tombes contenant cinq individus. La tombe (2.110) a été utilisée à deux reprises, mais dans un lap de temps assez long, ce qui suppose un marquage de surface. Il est notable de remarquer que cette tombe, orientée nord-est sud-ouest, respecte parfaitement l'architecture de l'extension du mausolée, tout en étant disposé perpendiculairement aux tombes du mausolée primitif. Ce même espace a accueilli l'inhumation d'un bébé déposée dans une fosse en pleine terre pourvue d'un calage de pierres (2.108). Une troisième tombe (2.119) contenant deux inhumations successives (IND 7 et IND 8) a été découverte le long du mur 2.104. Orientée nord-ouest sud-est, la tombe suit le tracé du mur 2.104. Elle a été creusée en pleine terre, mais a reçu un aménagement de quelques dalles calcaires latérales dressées sur champ et des moellons au pied et à la tête (fig. 5). Ce type d'aménagement est identique à celui de la tombe adossée à la façade occidentale du bâtiment II. $2^{5}$ et peut plaider en faveur d'une datation contemporaine. La tombe ne contenait pas de mobilier funéraire, cependant, son comblement a fourni un mobilier archéologique varié, dont deux monnaies en bronze de l'Antiquité tardive ${ }^{6}$. 
Fig. 5 - Mirine-Fulfinum, tombe 2.119 dans le mausolée II.1B.

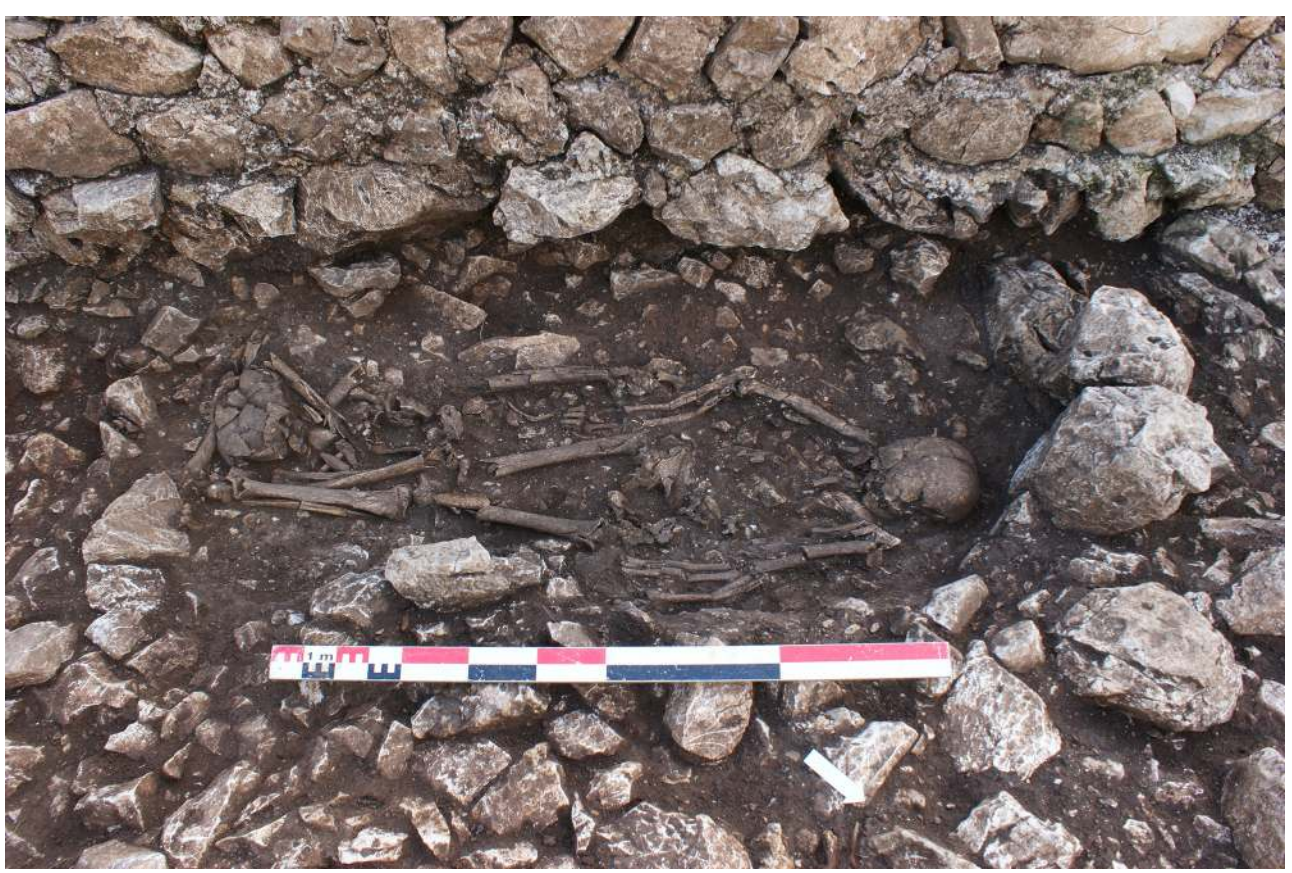

E. Balić, 2014.

7 La campagne 2014 a étendu la fouille à l'extérieur du mausolée, dans la zone nord-est. Un caveau maçonné (2.118) est adossé contre le parement externe du mur nord (fig. 6). Aucune inhumation n'a été retrouvée in situ à l'intérieur.

Fig. 6 - Mirine-Fulfinum - tombe 2.118 au chevet du mausolée II.1A.

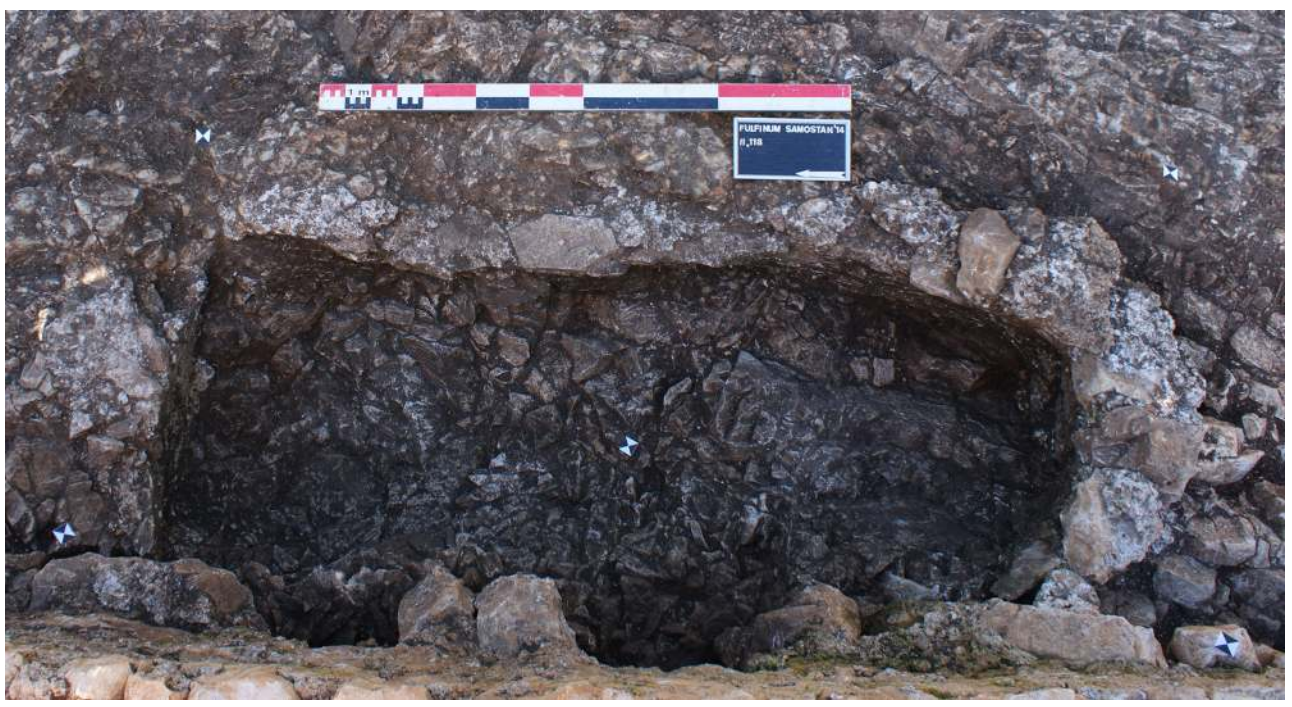

E. Balić, 2014.

En revanche, son comblement (2.1030) contenait des ossements humains disloqués, ainsi qu'un grand nombre de fragments de céramique et de verre. La construction du caveau est assez rudimentaire puisqu'il s'agit d'une fosse semi-rupestre soulignée par un cordon de petits moellons non taillés liés par un mortier de chaux de mauvaise qualité. 
La nécropole organisée autour de ce mausolée s'étendait vers le nord-est, où nous avons poursuivi les fouilles en 2014. Ici, deux sépultures d'immatures, déposées dans des amphores africaines tardives ( $\mathrm{V}^{\mathrm{e}}-\mathrm{VII}^{\mathrm{e}} \mathrm{s}$.), ont été découvertes, ainsi qu'une sépulture en pleine terre. La première sépulture d'immature (2.121, IND 11) utilisait une grande amphore presque entièrement préservée ( $80 \mathrm{~cm}$ de longueur) (fig. 7). Afin de placer l'immature défunt (IND 11), le fond du récipient a été cassé, puis recouvert par un fragment d'un autre récipient en céramique (2.1041). Le tout a été posé au fond d'une petite fosse creusée en partie dans le rocher, avant d'être calée par un comblement composé de petits blocs et de cailloutis (2.1043) qui maintenaient l'amphore en place.

Fig. 7 - Mirine-Fulfinum - tombe en amphore 2.121 découverte au chevet du mausolée II.1A.

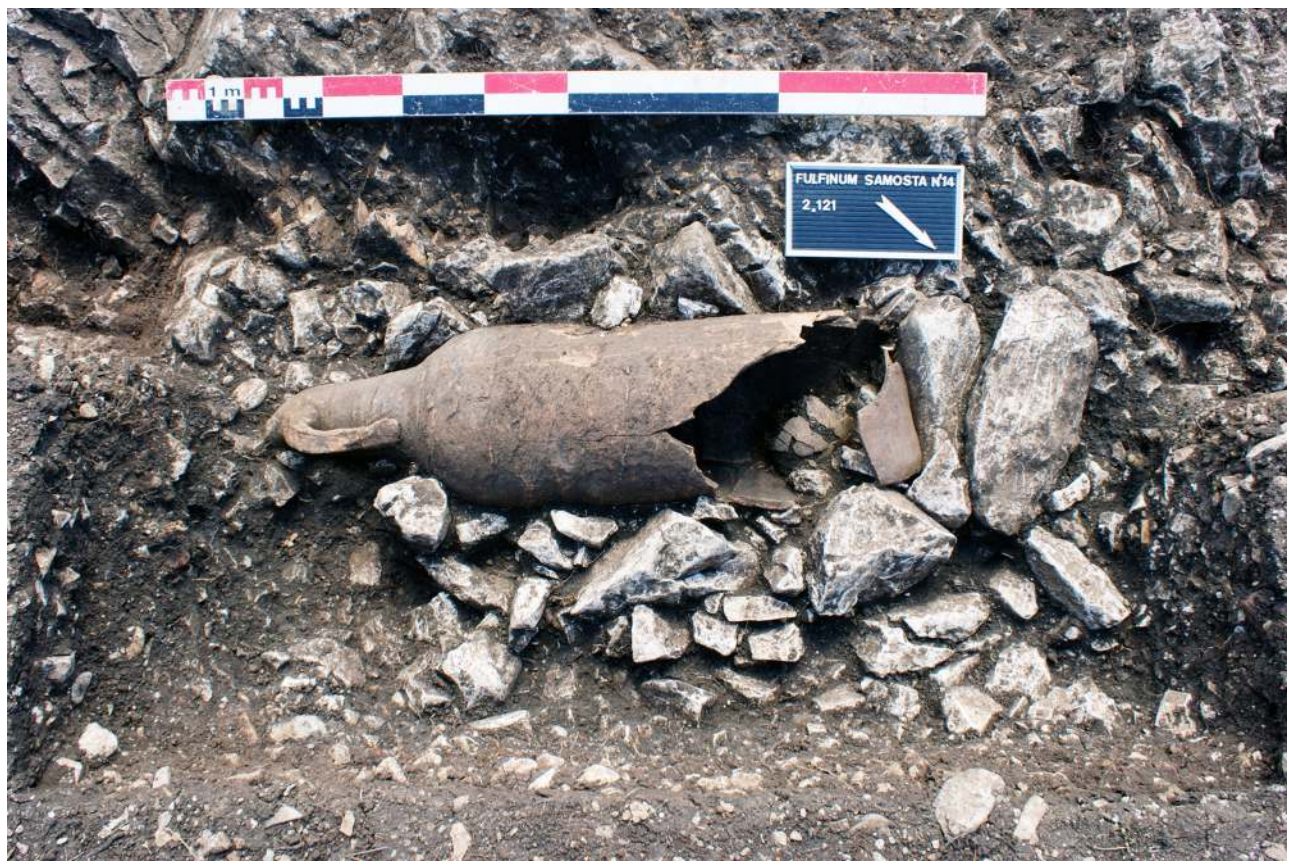

E. Balić, 2014.

9 La deuxième sépulture en amphore (2.122, IND 10) était moins bien préservée: la longueur totale de l'amphore (2.1031), sans le col et la lèvre, qui ont disparu, s'élevait à $63 \mathrm{~cm}$. La partie sommitale du contenant, placée de même manière dans une fosse que la première sépulture décrite, a été écrêtée par des perturbations postérieures liées à l'amoncellement d'un tas d'épierrement en limite de parcelle de l'époque moderne. On peut remarquer ici que, contrairement à la première sépulture, l'insertion du défunt a été opérée par le col de l'amphore; la partie cassée a ensuite été complétée par d'autres fragments de poterie et de la céramique architecturale (2.1032). Une sépulture (2.123) orientée nord-ouest - sud-est a été reconnue dans la coupe stratigraphique en limite septentrionale de la fouille.

Des trous de poteaux (trois sont assurés : 2.1036, 2.1038 et 2.1039) et les vestiges d'un foyer (2.125) témoignent de l'existence d'une structure légère adossée contre le mur nord du mausolée. L'alignement des trous de poteaux est parallèle au mur et distant de $0,90 \mathrm{~m}$; leur diamètre (d'environ $12 \mathrm{~cm}$ ) et leur faible éloignement du mur suggèrent une sorte d'appentis de bois. La présence de cet abri nous interpelle, sans que l'on puisse s'assurer 
de sa fonction : abri pour la tombe extérieure 2.118 ou pour des repas funéraires (foyer) en lien avec les tombes $2.118,2.121$ et 2.122 .

\section{Mausolée II.3}

11 Ce petit édifice d'un simple plan quadrangulaire a été mis au jour sous un imposant tas d'épierrement en 1999 lors de la campagne de fouille entreprise dans le cadre du camp archéologique d'été - sous la direction de Nino Novak et de Claudia Pizzinato - organisé par la commune d'Omišalj et le bureau de l'UNESCO de Venise. Les murs sud et est ont été dégagés, ainsi que le sol de l'édifice, tandis que les murs nord et ouest sont restés partiellement ensevelis. Le segment d'une colonne antique monolithe, scindée en deux dans sa longueur, découverte dans le petit édifice, avait alors été interprété comme le couvercle d'une hypothétique tombe. Après les travaux du nettoyage, et malgré l'état incomplet de la fouille, il a été décidé de restaurer partiellement le sol du bâtiment. Une chape du béton blanc (2.3009) a donc été coulée directement sur le substrat rocheux, aux emplacements où le sol d'origine manquait. La colonne scindée a été laissée en place alors que le nouveau sol était coulé autour en épousant sa forme... Lors de la révision de fouille entreprise en 2014, nous avons souhaité mieux connaître le plan du bâtiment, ainsi que son environnement proche (fig. 8).

Fig. 8 - Mirine-Fulfinum, vue générale depuis le nord du mausolée II.3.

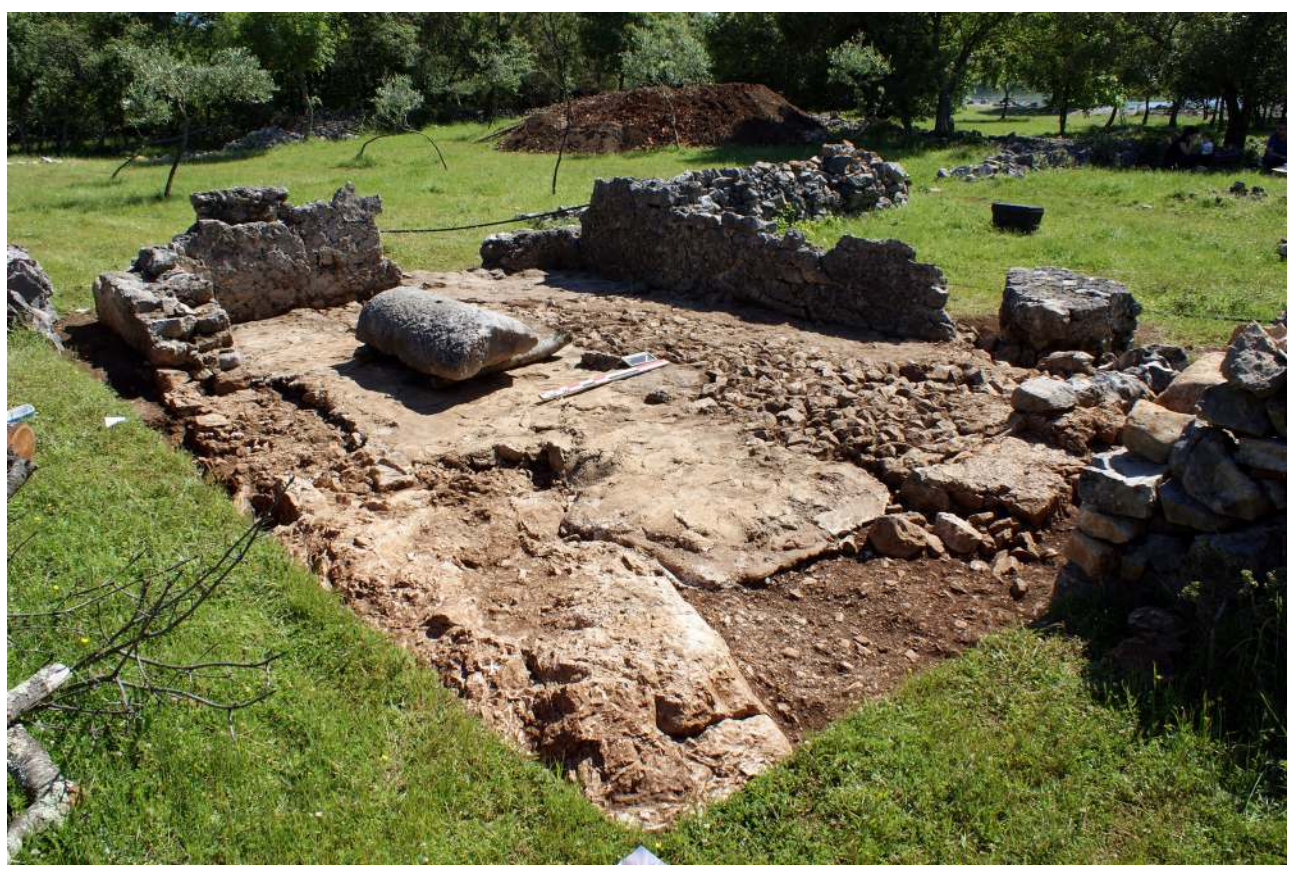

M. Čaušević-Bully, 2014.

12 Le bâtiment II.3 est un édifice de plan rectangulaire de dimensions modestes $(4,86 \times 9 \mathrm{~m})$, construit directement sur le rocher, et dont les murs sont préservés entre 0 et $0,96 \mathrm{~m}$ audessus du niveau du sol interne (fig. 9). 
Fig. 9 - Mirine-Fulfinum, relevés en plan et en élévation du mausolée II.3.

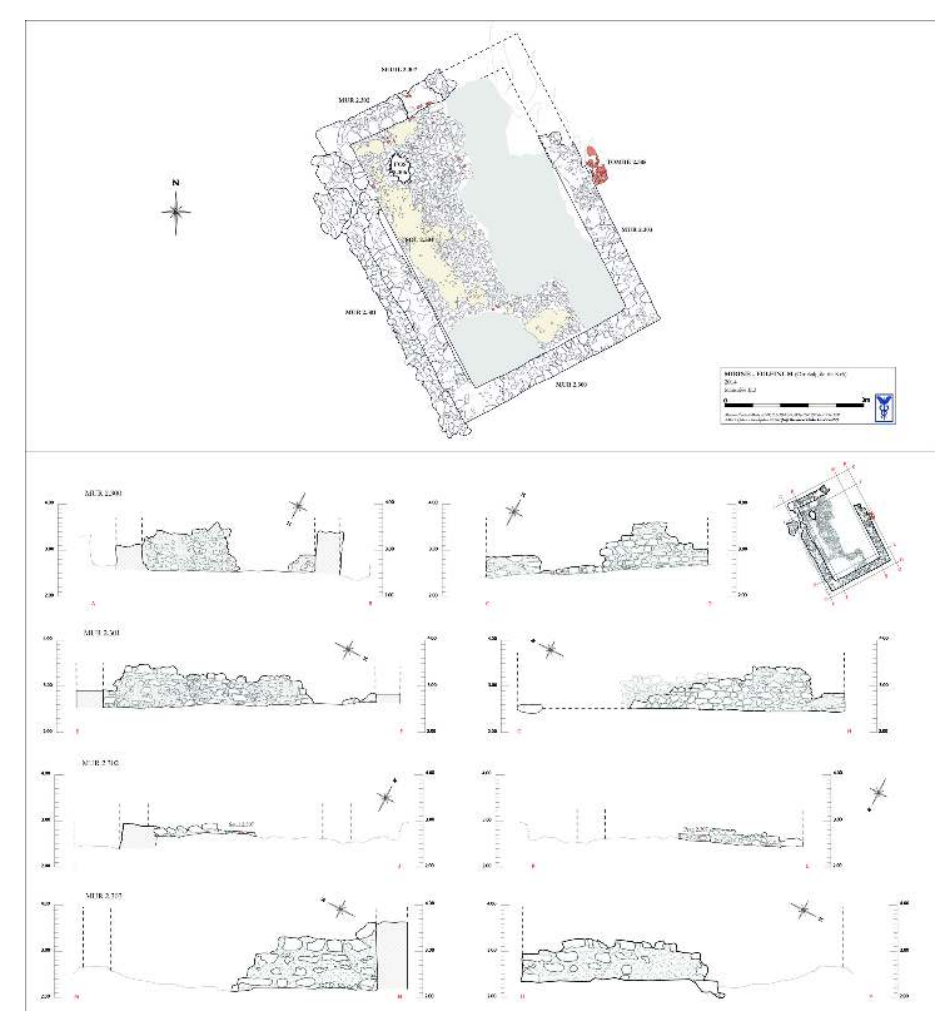

D’après Société Kaducej et D. Vuillermoz.

Ses fondations, de même largeur que les élévations - entre 0,53 et 0,55 m - épousaient les irrégularités du sol géologique. En raison de la faible largeur des fondations, un cordon de pierre (2.3010) de confortement a été ajouté dans un second temps le long du mur 2.301 afin de compenser la déclivité naturelle du sol naturel. Les murs du bâtiment II.3 sont construits en opus incertum et sont proches dans leur mise en œuvre - avec notamment la même taille des blocs et l'utilisation abondante d'un mortier de chaux -, des murs de la première phase du mausolée (II.1A) (fig. 9). Les vestiges d'une installation accolée au parement interne du mur 2.303 sont encore visibles à une quinzaine de centimètres audessus du sol 2.304. Au centre du mur 2.302 se trouvent les vestiges d'un seuil (2.307) formé par un lit de petits cailloutis et de fragments de briques noyés dans une chape d'un fin mortier lissé. Seul subsiste le montant sud-ouest d'une ouverture située à 1,4 $\mathrm{m}$ de l'angle interne, ce qui permet de restituer une largeur de 0,90 m. La situation de la porte nous incite à penser que le mausolée II.3 est lié à l'église de Mirine.

À l'intérieur de l'édifice, nous avons achevé la fouille du sol (2.304); celui-ci est constitué d'une couche de cailloutis et de fragments de tegulae (2.3005) en préparation d'une couche du mortier formant le niveau de circulation (2.3006). Plusieurs lacunes dans le sol nous ont permis de descendre sous le radier et d'établir que ce dernier repose directement sur le rocher ou sur une couche de nivellement compacte de terre battue et de petits cailloux (2.3007) contenant quelques petits tessons de céramique.

La nécessité de conserver le sol 2.304 ne nous permet pas savoir si celui-ci a scellé une tombe primitive. Mais une lacune dans le sol laisse apparaître une potentielle structure - tombe ? - constituée de deux blocs posés à plat dans la partie sud-est. 
En absence de la découverte assurée d'une tombe à l'intérieur du bâtiment II.3, il est difficile de se prononcer sur sa fonction exacte. Contre le mur 2.303, accolé au parement extérieur et donc postérieur, nous avons cependant découvert une tombe en amphore - préservée sur $86 \mathrm{~cm}$ de longueur - d'un immature (2.305, IND 12), identique à celles identifiées au nord-est du mausolée II.1A.

L'emplacement du bâtiment II.3, au cœur de la nécropole tardo-antique, comme la présence d'une inhumation en amphore accolée à son parement, plaide en faveur de l'identification d'un second mausolée, probablement contemporain du mausolée II.1A.

\section{Conclusion}

Les recherches engagées ces deux dernières années participent de manière essentielle à la connaissance de l'évolution du site de Fulfinum-Mirine durant l'Antiquité tardive, qui voit l'installation sur les marges de la ville d'une nécropole au IV $\mathrm{s}$., rapidement dotée de mausolées dans le $\mathrm{V}^{\mathrm{e}} \mathrm{s}$. et d'un important complexe paléochrétien contemporain qui perdure au moins jusqu'au VIII ${ }^{\mathrm{e}}$ s. (fig. 10). Le mausolée II.1 témoignerait du maintien de cellules familiales à Fulfinum au $\mathrm{V}^{\mathrm{e}} \mathrm{s}$., alors que l'on considérait, il y a encore peu, que la ville avait été définitivement abandonnée à la fin $\mathrm{du} \mathrm{IV}^{\mathrm{e}} \mathrm{s} .^{7}$ L'agrandissement du mausolée (II.1B) et la réutilisation des tombes 2.110 et 2.119 indiquent une utilisation sur un temps long, qui devra être précisé par des datations radiocarbones. Rappelons que les sépultures fouillées dans le vestibule de la basilique et dans les portiques de l'atrium attestent une utilisation funéraire des espaces au moins jusqu'au VIII ${ }^{\mathrm{e}} \mathrm{s}$.

Fig. 10 -Mirine-Fulfinum, plan topographique du site, état 2014.

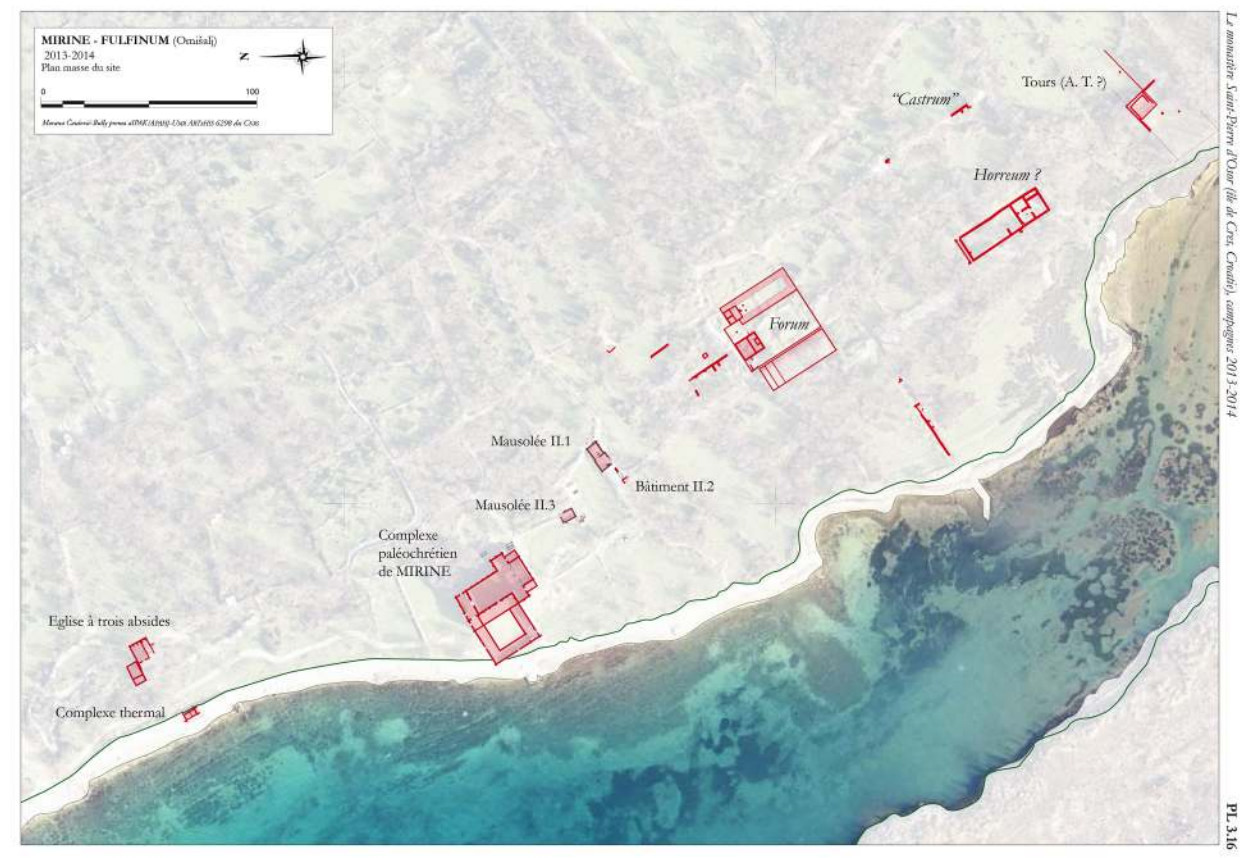

Plan M. Čaušević-Bully.

Ces mausolées sont les premiers découverts dans le Kvarner ${ }^{8}$ et on manque dès lors d'éléments de comparaisons. Mais dans l'attente d'un développement de leur étude 
- concomitante de celle de l'ensemble des données d'ores et déjà rassemblé sur le site -, on notera l'absence de tous éléments - conservés - de décoration (marbre, peintures, stucs etc.), contrastant avec une formulation architecturale élaborée pour le mausolée II.1. Cette considération repose sur le choix d'un espace monumentalisé par un très probable voûtement, supporté par des murs gouttereaux dotés de contreforts.

17 La question qui demeure est celle de la nature de la population inhumée dans ces mausolées. En l'absence d'inscriptions comme de mobilier à caractère chrétien, on ne peut être assuré d'être en présence de tombes chrétiennes, mais pourrait-il en être autrement dans un tel contexte au $\mathrm{V}^{\mathrm{e}} \mathrm{s}$. ? Il est en revanche désormais à exclure que les mausolées se développant au sud-est du complexe paléochrétien aient appartenu au monastère, contrairement aux premières hypothèses de travail soulevées dans les années 1990. Et la révision en cours de l'étude anthropologique ${ }^{9}$ portant sur les inhumations fouillées entre 2000 et 2005 dans l'atrium et le vestibule, tend à contredire l'hypothèse d'un recrutement exclusivement masculin qui aurait pu correspondre à une communauté de clercs ou de moines. La question d'un monastère à l'emplacement du complexe paléochrétien de Mirine reste entière.

\section{Martinšćica, île de Cres (quatrième campagne) : fouille de l'abside de Martinšćica 2}

Le complexe antique et paléochrétien de Martinšćica fait l'objet de recherches archéologiques à travers des sondages et des relevés topographiques comme d'élévations depuis 2011. Les trois premières campagnes, bien que limitées dans leurs ampleurs, ont cependant déjà permis de dresser un état des lieux du site, de proposer un nouveau plan et un premier phasage de la grande église dite de plan en " croix grecque », ainsi qu'une étude de ses élévations à travers des relevés d'archéologie du bâti et un travail de restitution 3D. Loin d'être isolée au fond de sa baie, les premières recherches permettent de conclure que la grande église paléochrétienne (Saint-Martin?) Martinšćica 1 et 1bis - pour sa chapelle latérale sud -, est liée à un établissement antique dissimulé sous un épais couvert forestier et des tas d'épierrements, et que l'on identifie désormais comme une villa maritime. Les sondages ouverts en 2013 avaient permis de localiser des maçonneries particulièrement bien conservées en élévation et de définir plusieurs états de constructions entre le $\mathrm{III}^{\mathrm{e}} \mathrm{s}$. et l'Antiquité tardive. Et à une soixantaine de mètres au nord-ouest de la grande église, la prospection avait révélé les vestiges d'un mur semicirculaire, enregistré comme Martinšćica 2. Le sondage en 2013 n'avait pas permis de préciser le plan comme la fonction de cette construction que l'on pouvait identifier comme le sanctuaire d'un édifice de culte chrétien, l'abside d'un bâtiment antique, ou la tour d'un élément défensif ${ }^{10}$. Devant l'enjeu que représente son interprétation, nous avons donc opté en 2014 pour une fouille plus conséquente afin d'en circonscrire le plan, d'en définir la fonction et de conforter sa datation (fig. 11). 
Fig. 11 - Martinšćica, vue générale depuis le sud de l'abside en cours de fouille.

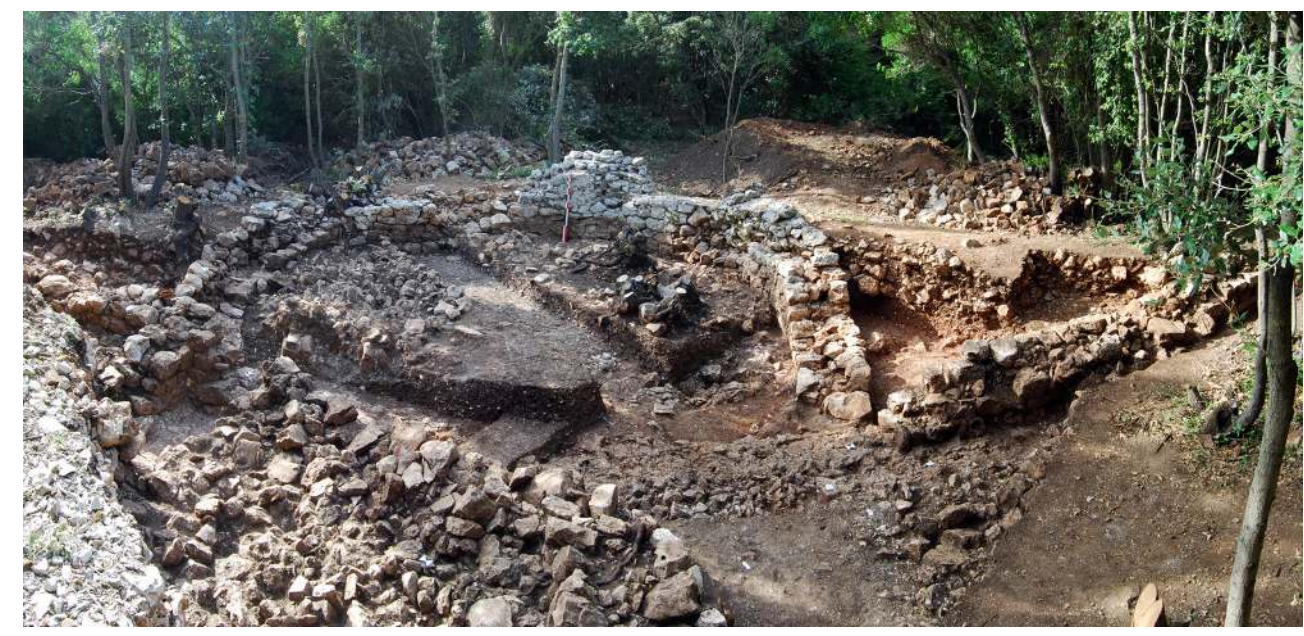

S. Bully, 2014.

\section{Principaux résultats}

19 Avant le démarrage de la fouille, le secteur de Martinšćica 2 (Espace VII) se présentait comme un sous-bois touffu qui recouvrait des tas d'épierrements desquels émergeait le mur semi-circulaire. Un important travail d'abattage des arbres et de débroussaillage a été nécessaire en préalable à la fouille.

Sans que l'on puisse actuellement les rattacher à des structures contemporaines, la fouille a livré deux éléments de mobilier qui pourraient constituer les premiers indices d'une occupation du site dès la première moitié du $\mathrm{I}^{\mathrm{er}} \mathrm{s}$. ap. J.-C. : il s'agit d'un as de cuivre frappé à Rome en 42 par Claude en honneur de son frère Germanicus (us 7.1005), et d'un fragment de tegula estampillé de l'époque de Caligula (us 7.1003) (fig. 12). 
Fig. 12 - Martinšćica, fragment de tegula estampillé de l'époque de Caligula.

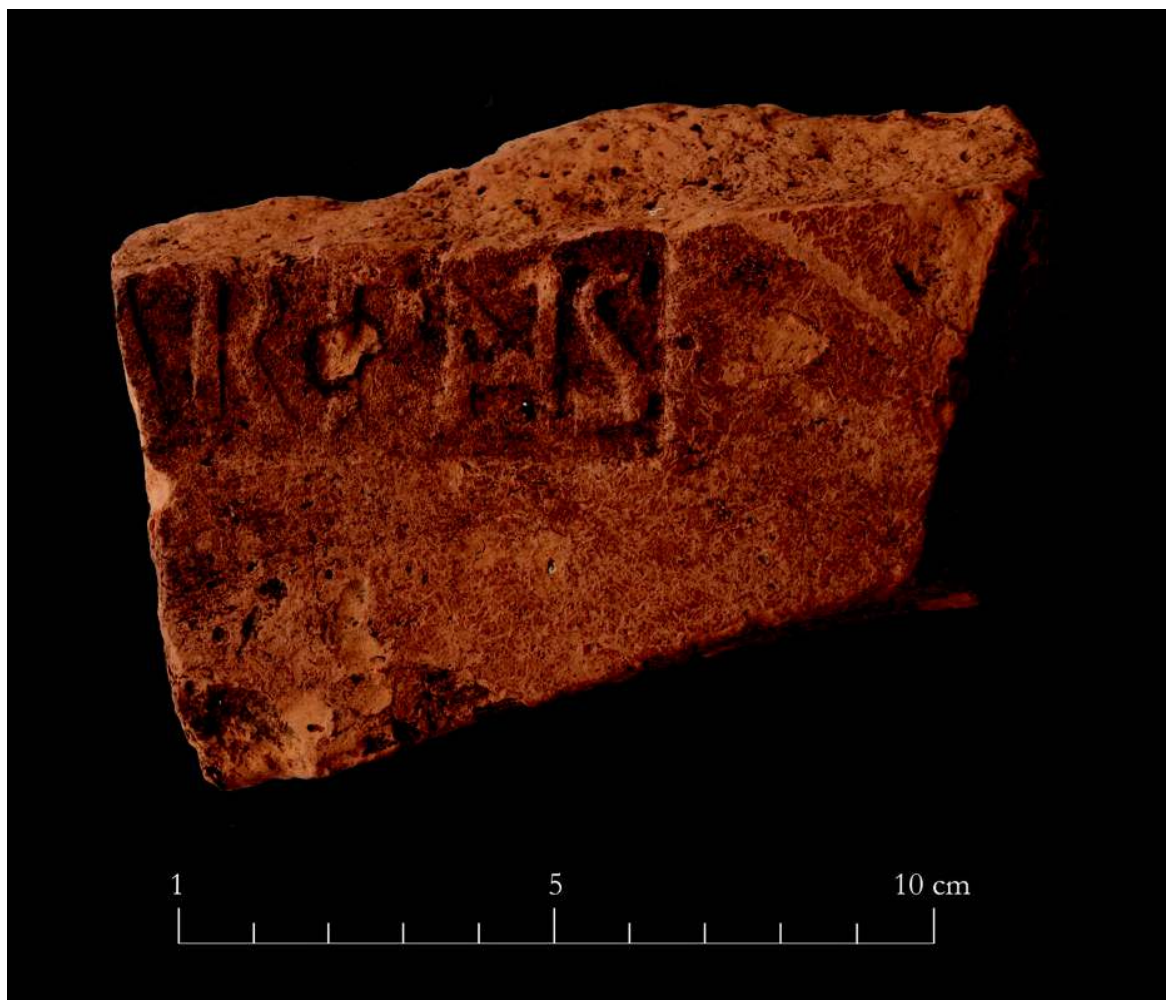

I. Valent, 2014.

Mais la première phase de construction reconnue est constituée par l'angle nord-ouest d'un vaste bâtiment subdivisé en au moins trois longues salles ou, moins probablement, en trois nefs parallèles (fig. 13). 
Fig. 13 - Martinšćica, relevés en plan des structures découvertes en 2014.

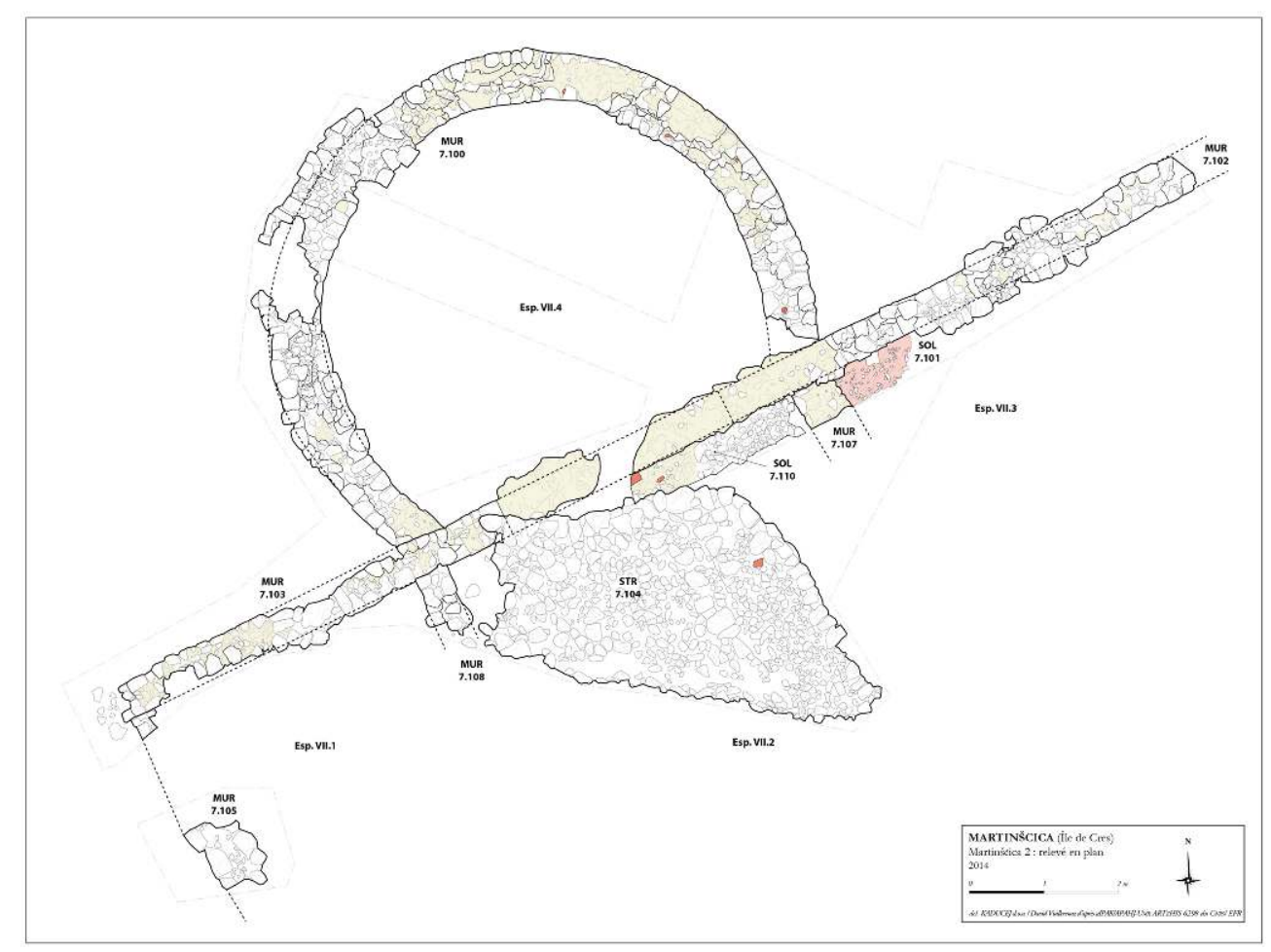

D’après Société Kaducej et D. Vuillermoz.

Le mur nord 7.102/7.103, reconnu sur une longueur de 15,75 m, semble s'achever à l'ouest en se retournant avec le mur 7.105 (observé en sondage), alors qu'il se poursuit en direction de l'est au-delà de l'emprise de la fouille. Un premier espace d'environ 3,40 $\mathrm{m}$ de large (Esp. VII.1) est limité par les murs 7.105 et 7.108; un second espace (VII.2), plus large, de 5,16 m, est limité par les murs 7.108 et 7.107, bordé lui-même à l'est par un troisième espace (VII.3) dont on ne connaît pas la l'extension orientale. L'espace central VII.2 conserve des vestiges d'un sol très compact (7.110) autour de la cote 3,95 m, formé d'une couche d'argile jaune sur un radier de cailloutis ragréé par des couches de mortier et des agrégats d'un béton de tuileau. À la même cote altimétrique, l'espace VII.3 était couvert d'un sol en béton de tuileau (cocciopesto ?) coulé sur un radier de cailloutis (sol 7.101). Le mur 7.102/7.103 mesure seulement 0,49 $\mathrm{m}$ de largeur ; il est conservé sur une élévation maximale de $0,60 \mathrm{~m}$. Le mur perpendiculaire 7.108 est plus étroit encore avec $0,44 \mathrm{~m}$ de largeur, mais de $0,56 \mathrm{~m}$ avec son talon de fondation; il est conservé sur une élévation de 0,46 m. Le mur parallèle 7.107 est arasé, mais mesurait 0,61 $\mathrm{m}$ de largeur.

21 Cette première phase - reconnue - de construction se caractérise par la mise en œuvre d'un petit appareil de moellons équarris, disposés en assises régulières soulignées par d'épais joints de mortier blanchâtre (fig. 14). 
Fig. 14 - Martinšćica, détail du parement extérieur du mur 7.102.

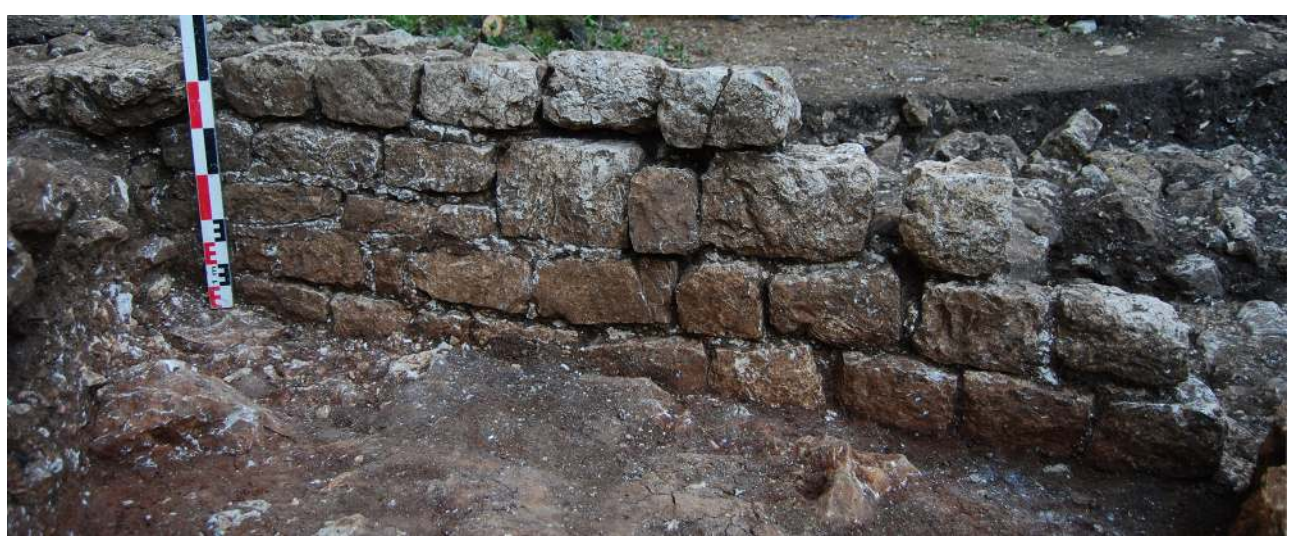

S. Bully, 2014.

Ce mode de construction peut être rapproché de celui observé dans le sondage opéré en 2013 dans le bâtiment L. Dans l'attente d'une étude plus détaillée du mobilier, nous serions donc en présence d'un bâtiment datable des $\mathrm{III}^{\mathrm{e}} \mathrm{IV}^{\mathrm{e}} \mathrm{s}$. par comparaison du mode de construction.

Dans une seconde phase, l'abside 7.100 a été greffée contre le parement extérieur du mur nord 7.102/7.103 (fig. 15).

Fig. 15 - Martinšćica, abside outrepassée de la villa antique tardive en cours de fouille.

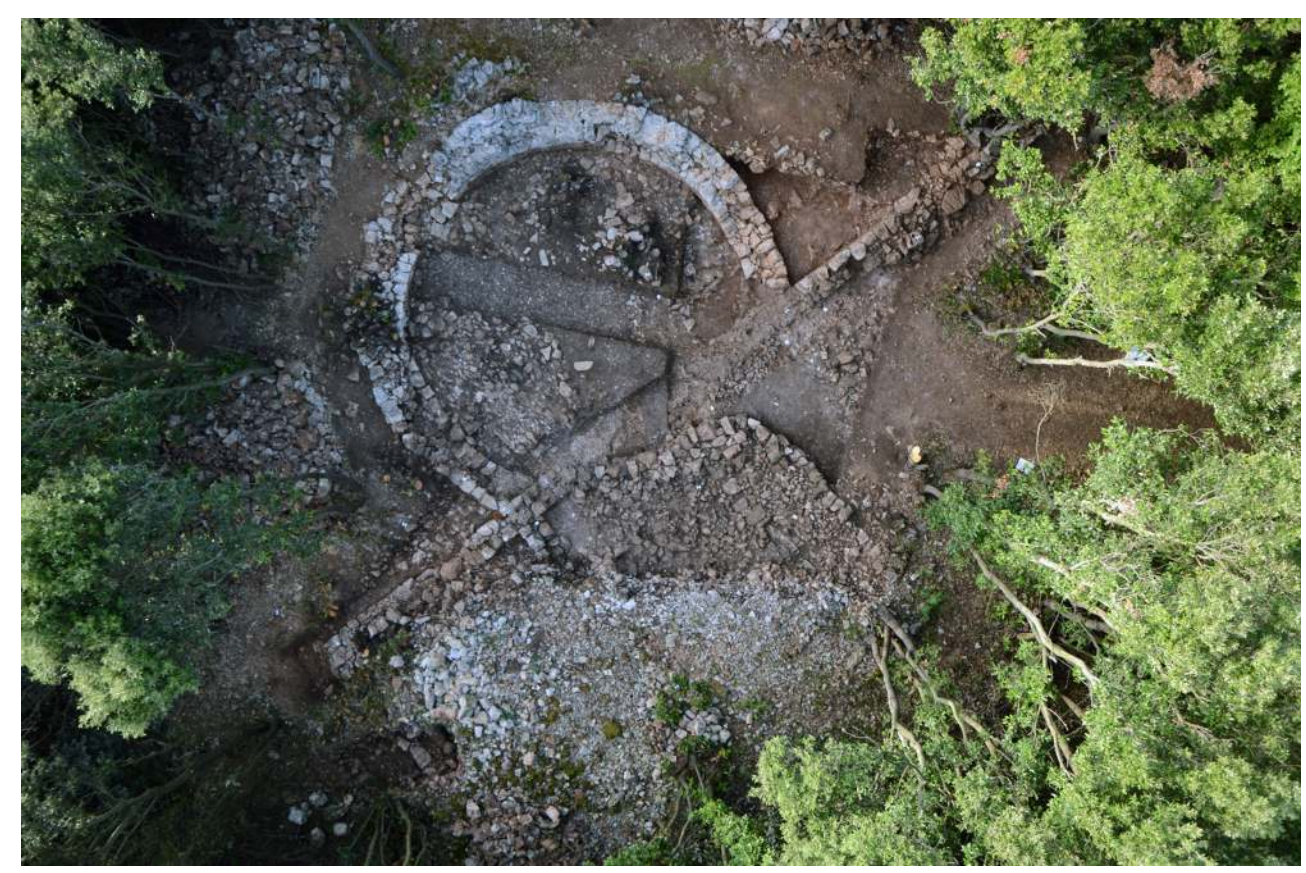

Société Kaducej, 2014.

Cette adjonction a entraîné l'arasement jusqu'au sol du segment du mur nord compris entre les deux murs perpendiculaires 7.108 et 7.107 , afin d'établir une communication avec le nouvel espace absidial (VII.4). Mais l'extrémité orientale du mur 7.103 déborde de la jonction avec l'abside sur un court segment de $0,80 \mathrm{~m}$, formant ainsi une tête de mur susceptible d'avoir supporté un arc d'environ 3,30 m de largeur (fig. 16). 
Fig. 16 - Martinšćica, détail de l'interruption du mur 7.103 formant la tête de mur de l'arc d'entrée dans l'abside 7.100.

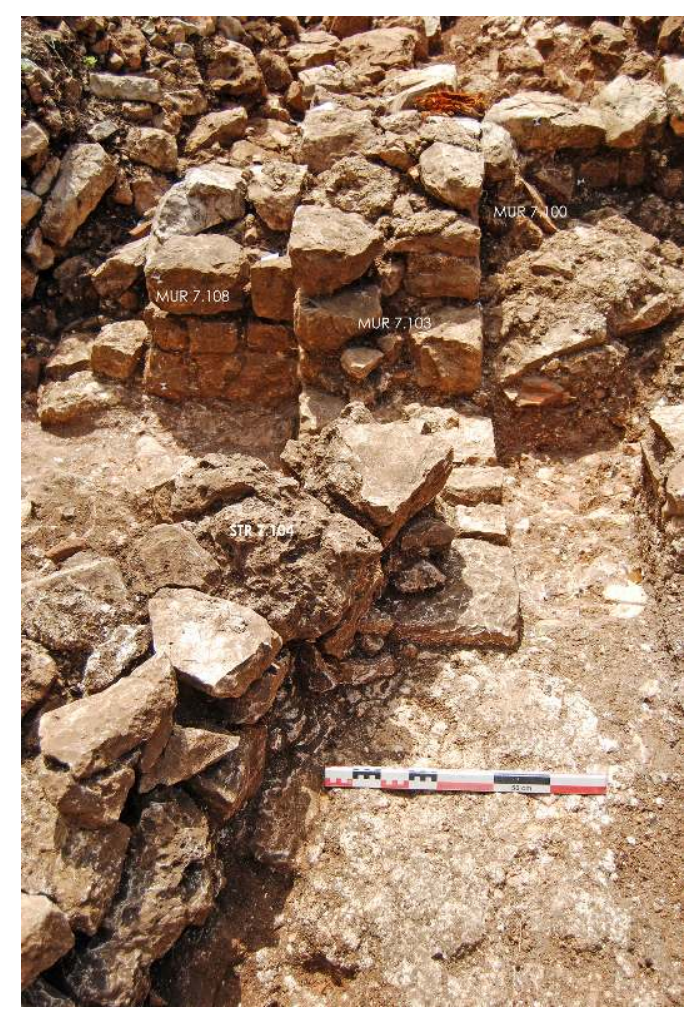

S. Bully, 2014.

La lecture de la stratigraphie n'a cependant pas permis de déterminer si la construction de l'abside formait l'augmentum méridional du seul espace central VII.2, ou d'un nouvel espace plus vaste formé par l'arasement du mur 7.107.

Conservée sur une élévation maximale de $1,16 \mathrm{~m}$, l'abside suit un tracé semi-circulaire clairement outrepassé; elle mesure intérieurement 4,90 m à sa corde, par 4,90 m de profondeur pour un diamètre maximum de 5,82 $\mathrm{m}$. Son mode de construction la distingue clairement des maçonneries de la phase précédente puisqu'il s'agit d'un mur en opus incertum, de 0,68 $\mathrm{m}$ de largeur, qui conserve des traces d'enduits blancs à l'intérieur (fig. 17) comme à l'extérieur. 
Fig. 17 - Martinšćica, détail du parement interne enduit de l'abside 7.100.

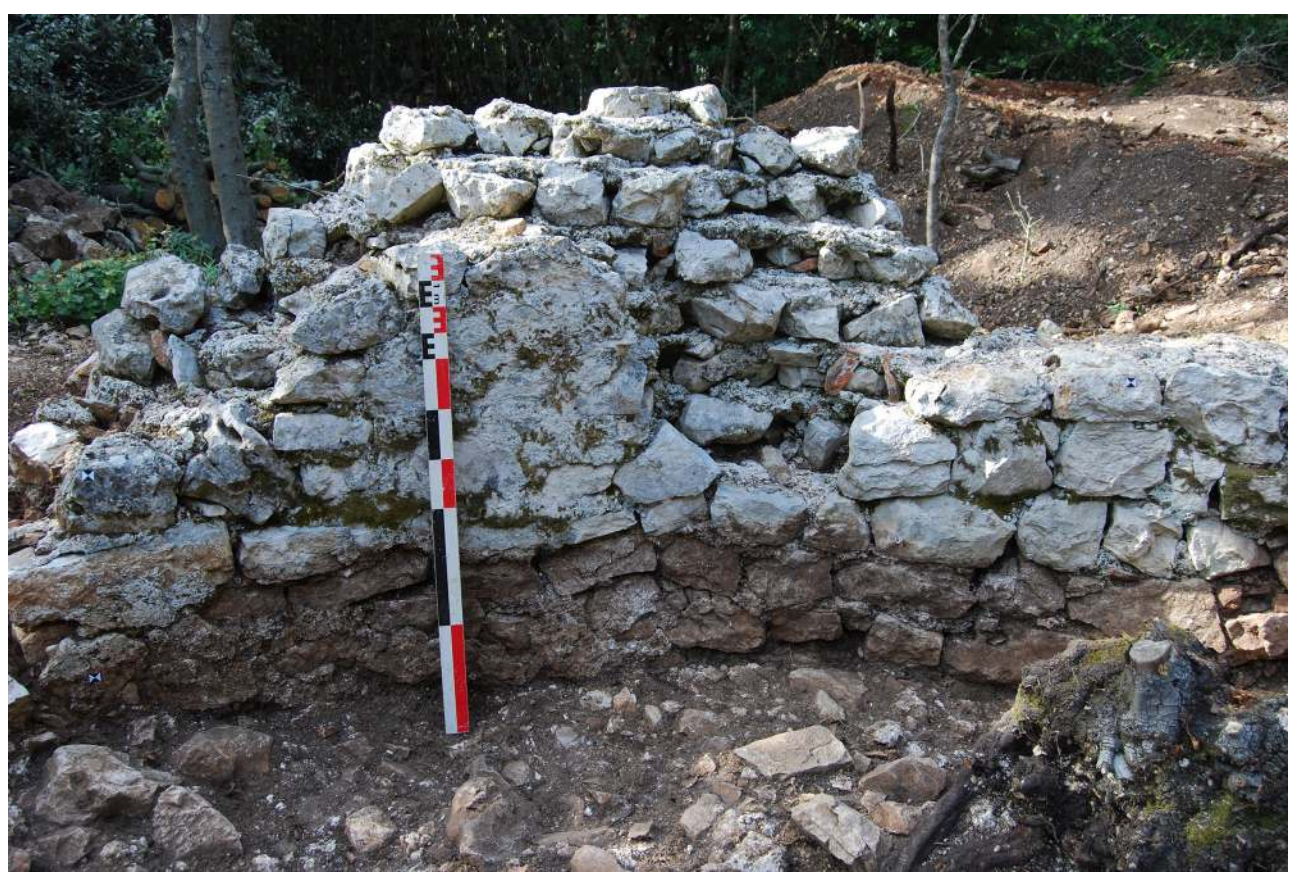

S. Bully, 2014.

Contrairement aux espaces VII.2 et VII.3, aucun sol n'est conservé dans l'abside, indiquant que le niveau de celui-ci était plus haut d'une ou de plusieurs marches. La nature de ce sol nous échappe également, mais les nombreuses briquettes d'un opus spicatum, contenues dans la couche de démolition 7.1003 de la structure postérieure 7.104, pourraient en provenir. En l'absence de mobilier marqueur, c'est encore la chronologie relative et le mode de construction qui plaident en faveur d'une datation dans l'Antiquité tardive. L'écrêtement des sols et les perturbations postérieures ne permettent malheureusement pas de connaître la durée d'occupation du bâtiment à abside.

Son abandon est marqué dans une troisième phase par l'aménagement d'une sorte de plate-forme de $\pm 0,40 \mathrm{~m}$ de hauteur, constituée d'un amoncellement organisé de blocs (Str. 7.104). Il pourrait s'agir d'un Recouvert par un épais tas d'épierrement (fig. 18), seul l'angle nord-est - $\pm 3,50 \times 3,50 \mathrm{~m}$ - de la « plate-forme » a été fouillé. 
Fig. 18 - Martinšćica, vue de la plate-forme 7.104 recouverte par le tas d'épierrement.

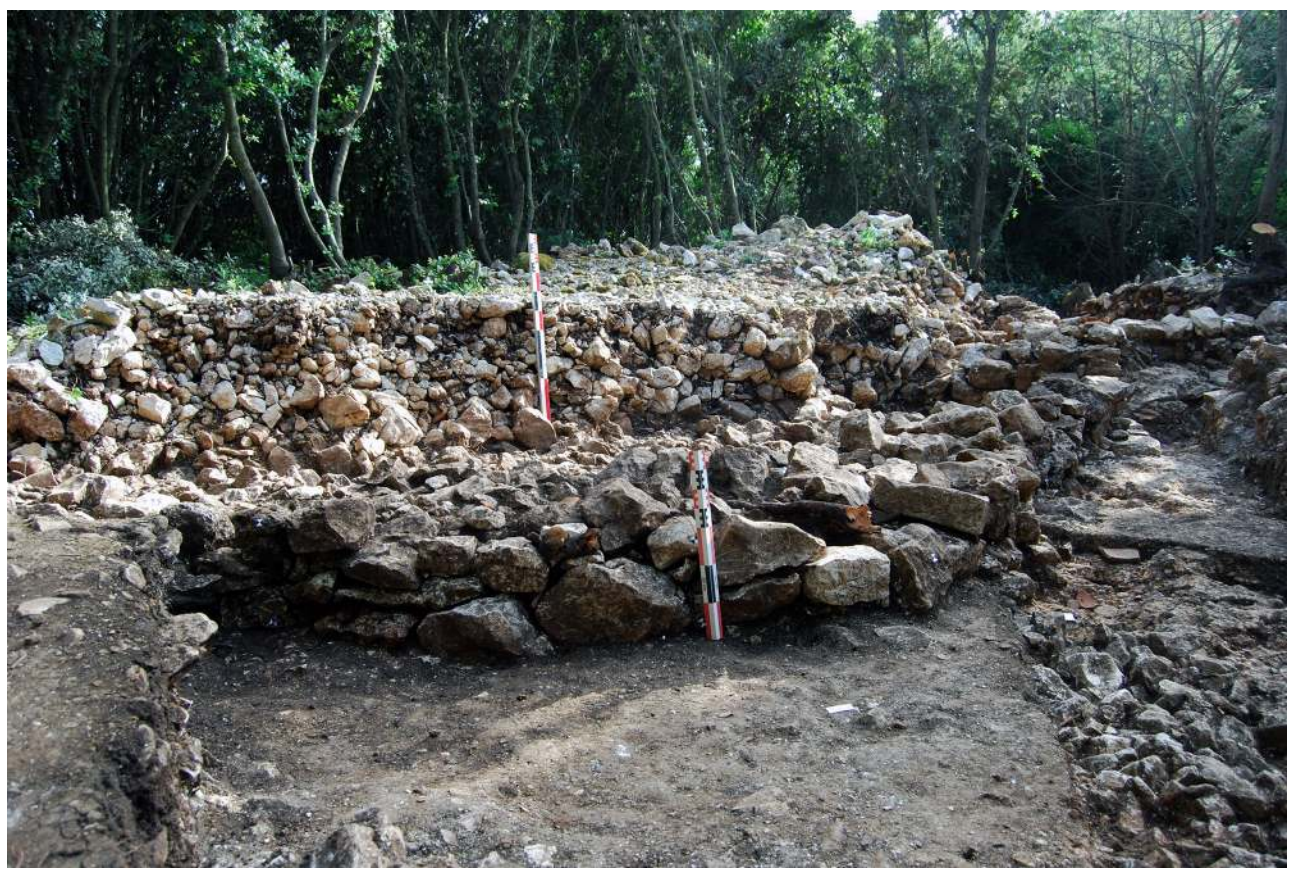

S. Bully, 2014.

Son organisation est marquée par la disposition de gros blocs non liés formant la limite de la plate-forme, alors que le remplissage (7.1003 et 7.1008) est assuré par des blocs plus petits et du cailloutis mêlé à une grande quantité de fragments de terre cuite architecturale, d'amphores, de céramiques communes, de verre, ainsi que des fragments de meules en basalte. La stratigraphie démontre que l'aménagement de la plate-forme tient compte des maçonneries des phases précédentes en partie conservées en élévation. Les gros blocs formant la limite de la plate-forme ont été déposés dans une tranchée (7.106) ouverte dans un niveau de circulation tardif (7.1014) qui avait scellé l'arrachement du mur 7.107 et recouvert le sol de béton de tuileau 7.101. La plate-forme est partiellement recouverte par la couche de démolition des maçonneries de l'abside, déjà en partie ruinée, avant d'être totalement enseveli sous un tas d'épierrement au moment d'une probable mise en culture de la parcelle. Nous sommes donc en présence d'un aménagement vraisemblablement pastoral, indatable en l'état (dans le haut Moyen Âge ? ), mais dont on a l'assurance qu'il a réutilisé des élévations antiques encore en partie conservées.

\section{Conclusion}

Les résultats préliminaires de l'étude du bâtiment enregistré comme " Martinšćica 2 ", au nombre desquels on constate l'absence de mobilier et d'installation liturgiques, comme de tombes, indiquent que l'on ne serait pas en présence des vestiges d'un édifice de culte, ni d'un élément défensif, mais plutôt d'une salle de réception, ou tout du moins d'un espace domestique, aménagée durant l'Antiquité tardive, suivant en cela une typologie bien connue $^{11}$. Cet espace absidial intervient en augmentum d'un vaste bâtiment des III ${ }^{\mathrm{e}}-\mathrm{IV}^{\mathrm{e}} \mathrm{s}$. de la villa maritime, dont des premiers indices d'occupation du I ${ }^{\text {er }} \mathrm{s}$. ap. J.-C. ont été mis au jour. On notera encore à ce propos la découverte en prospection dans le sous-bois d'un 
raté de cuisson de tegulae, indiquant la proximité de fours; ce témoignage, fugace, pourrait avoir son importance pour comprendre les raisons de l'installation d'un établissement antique classique dans ce secteur de la péninsule. Des compléments de relevés topographiques de maçonneries localisées dans le sous-bois, corrélées aux relevés des années précédentes, permettent également de proposer un nouvel état des lieux de la surface lotie et d'esquisser quelques grands traits du plan de la villa (fig. 19).

Fig. 19 - Martinšćica, plan général des vestiges mis au jour, état 2014.

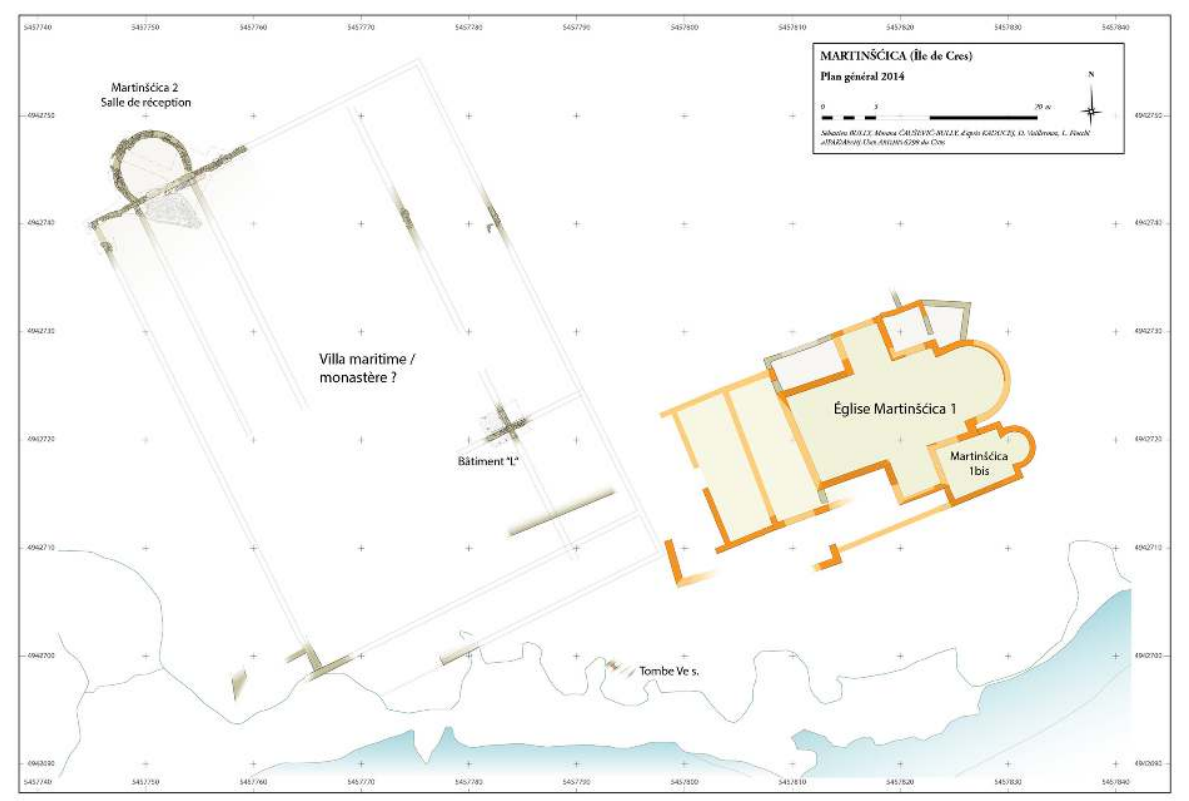

S. Bully et M. Čaušević-Bully d'après Société Kaducej, L. Fiocchi et D. Vuillermoz.

Une question majeure qui reste en suspens est celle de l'identité du dominus qui fit construire la salle absidée afin de mettre en valeur son rang social. Ici, c'est la conjonction de cet espace de représentation avec un édifice de culte, dont les dimensions et le parti architectural sont difficilement compatibles avec ceux d'une simple église patrimoniale, qui doit nous interpeller, même si, à ce stade des recherches, il reste encore délicat de se prononcer sur leur contemporanéité. Aussi, il sera nécessaire de préciser la datation des phases tardives de la villa par l'étude du mobilier et l'engagement de datations radiocarbones, comme d'affiner la datation de l'église. C'est un des objectifs de la fouille du chœur qui débutera en 2015. Dans l'état actuel des recherches, la question d'une possible réoccupation monastique reste ouverte, comme celle, qui sans être incompatible est tout autant indémontrable à ce jour, d'une villa épiscopale dans l'ager de la cité d'Osor. 


\section{Vestiges sur l'îlot de Lukovac, baie de Crnika, île de Rab (seconde campagne) : état des lieux et relevés topographiques}

La première campagne en 2013 avait été limitée à un dégagement superficiel de l'église repérée au centre de l'îlot et à un premier relevé. L'objectif de la campagne 2014 était de compléter le plan de l'église, mais surtout, d'établir un état des lieux de l'ensemble des maçonneries visibles à l'issue du débroussaillage de l'îlot ${ }^{12}$ (fig. 20).

Fig. 20 - Îlot de Lukovac, plan général des vestiges, état 2014.

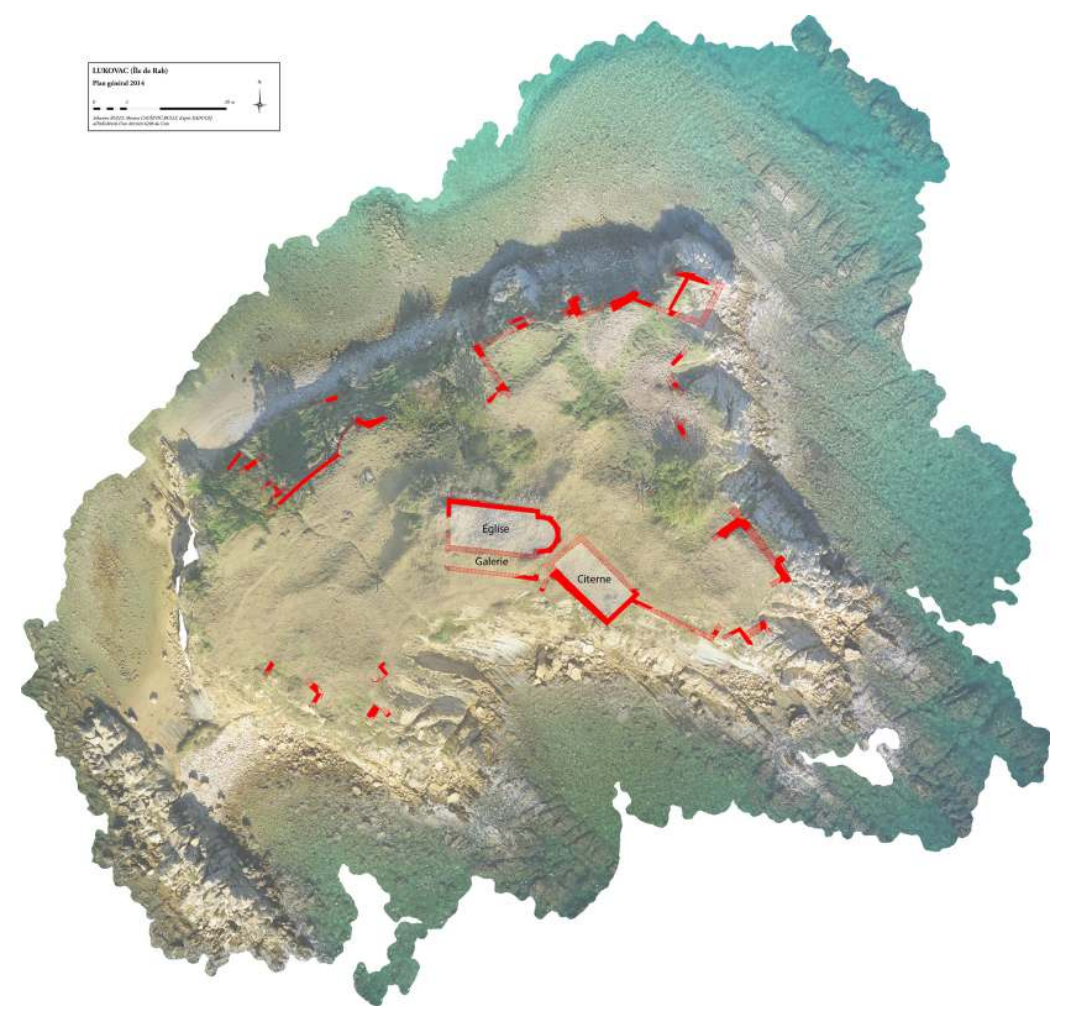

S. Bully et M. Čaušević-Bully d'après Société Kaducej.

Pour cette seconde intervention d'une semaine, nous avons bénéficié du concours d'agents communaux - doté de débroussailleuse - mis à disposition par la municipalité de Lopar. Les maçonneries repérées ont été nettoyées de manière superficielle afin d'en déterminer la largeur et l'orientation (fig. 21); un petit sondage a été ouvert pour confirmer l'identification d'une citerne. 
Fig. 21 - Îlot de Lukovac, repérage des structures et sondages.

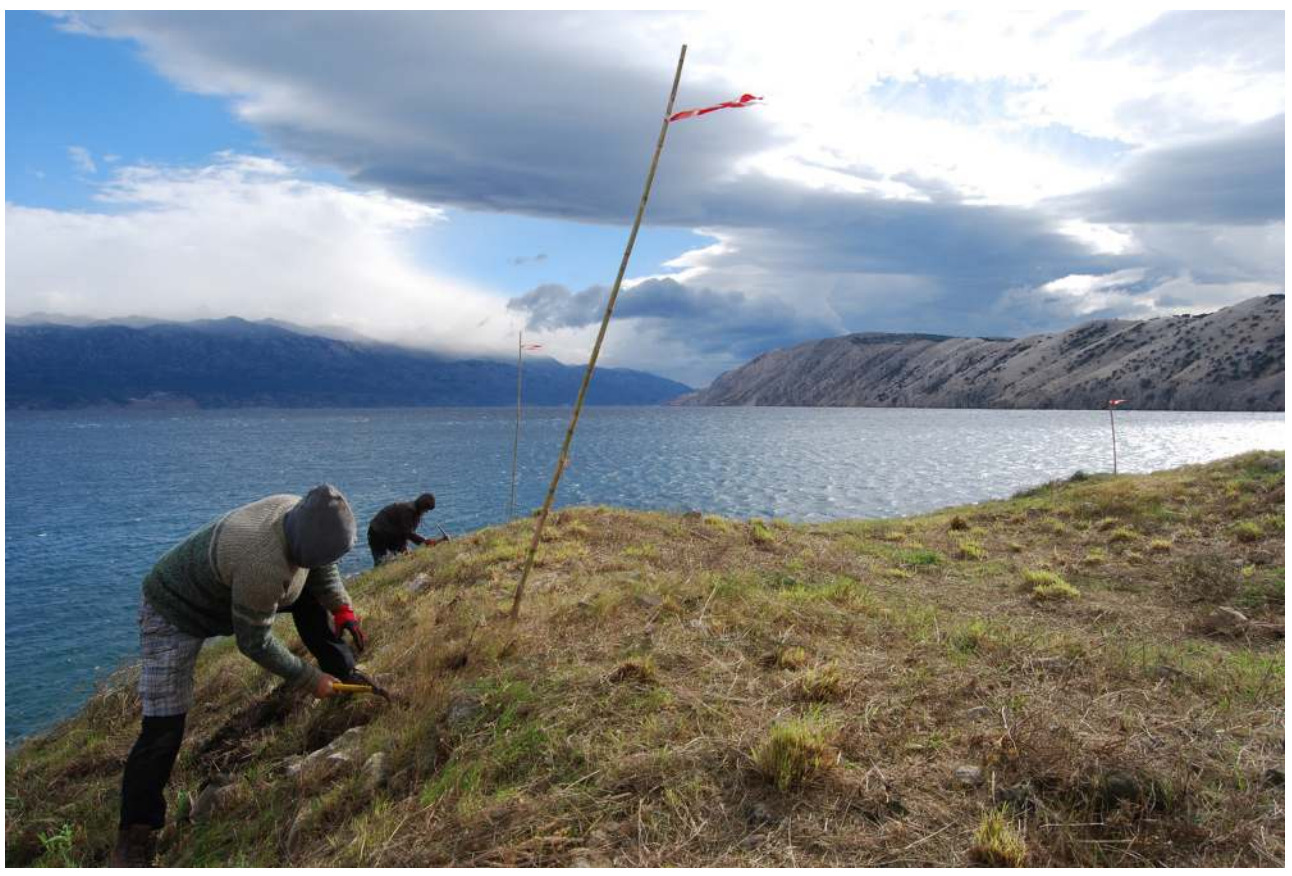

S. Bully, 2014.

\section{Principaux résultats}

L'église comporte une nef unique - dim. int. $\pm 12,70$ x 6,18 m - bordée d'une abside - diam. à la corde 4,40 m, prof. int. 2,85 m (fig. 22).

Fig. 22 - îlot de Lukovac, vestiges de l'église protobyzantine et de la citerne à son chevet.

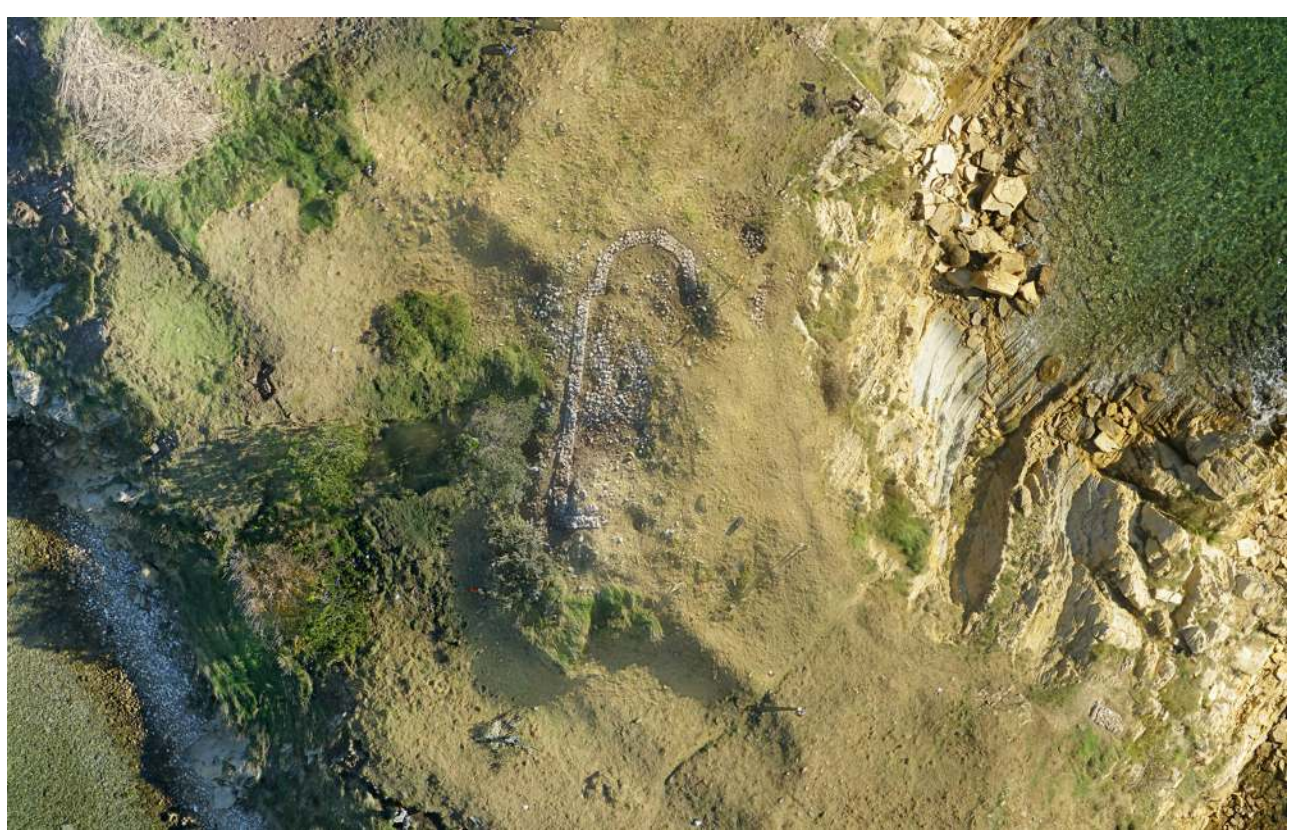

Société Kaducej, 2014. 
Le parement intérieur de l'abside suit un tracé semi-circulaire, alors que son parement extérieur est clairement polygonal dans sa moitié sud, mais semble suivre sur un tracé semi-circulaire dans sa moitié nord (fig. 23).

Fig. 23 - Îlot de Lukovac, nettoyage de l'arase de l'abside.

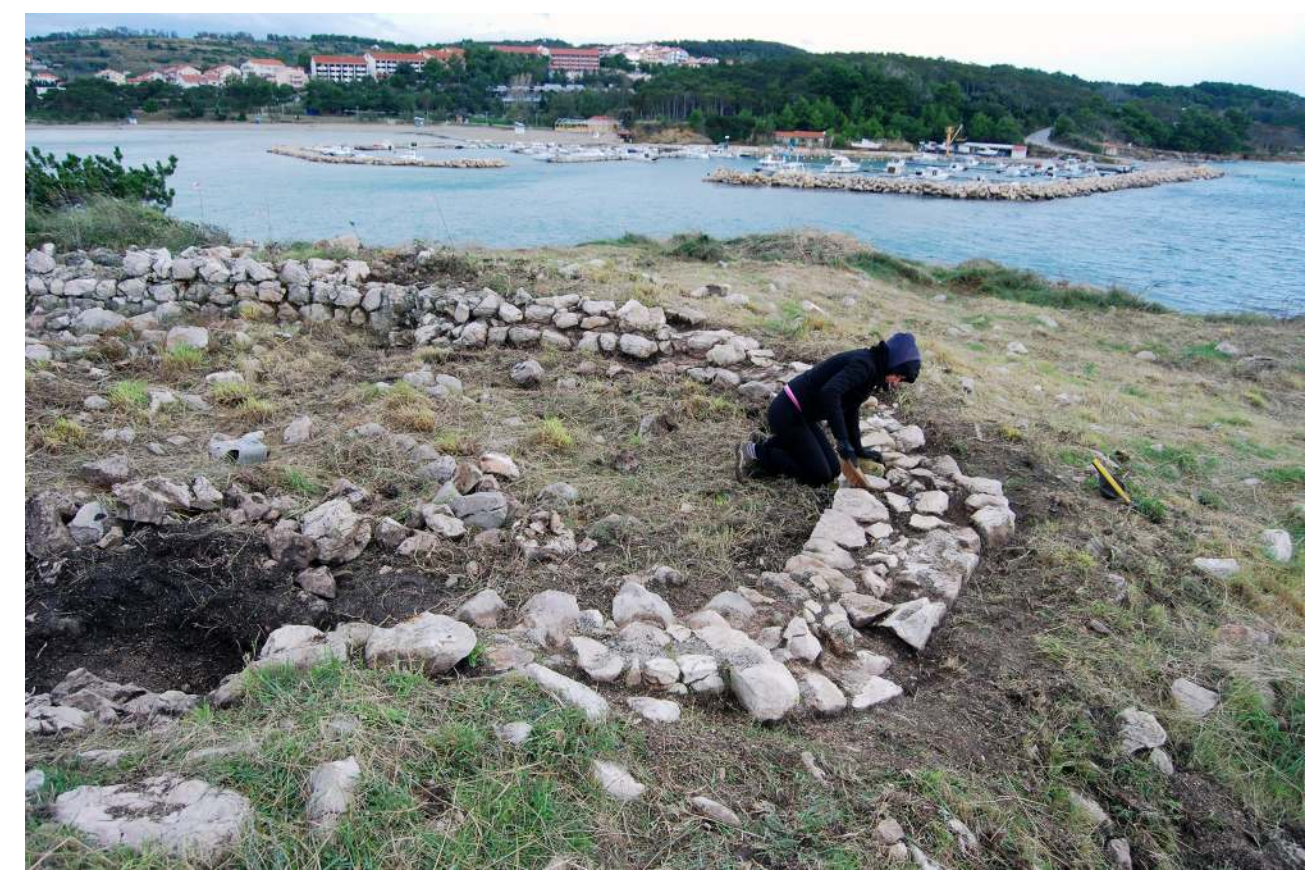

S. Bully, 2014.

Seule une fouille permettrait de s'assurer définitivement du plan de l'abside. En revanche, il est assuré que l'extrados est rythmé par quatre lésènes, alors que le mur gouttereau nord en possède deux. Les maçonneries en opus incertum mesurent $0,64 \mathrm{~m}$ de largeur pour la nef et $0,72 \mathrm{~m}$ pour l'abside. La largeur des murs et la présence de lésènes nous conduisent à restituer une voûte en cul-de-four dans l'abside, articulée avec une nef charpentée. La nef semble avoir été bordée d'une galerie au sud de 2,50 $\mathrm{m}$ de large; le mur sud de la galerie (mur-bahut ?) mesure $0,54 \mathrm{~m}$ de largeur, il se retourne à angle droit en direction de l'épaulement de l'abside par une maçonnerie légèrement plus large, de $0,62 \mathrm{~m}$. Une seule porte en façade a été reconnue, mais il est vraisemblable que l'on pouvait également accéder dans la nef depuis la galerie.

Seules quelques assises de l'église sont visibles et on ignore donc la hauteur conservée des élévations. Mais la topographie du site laisse entrevoir que les arases des murs émergent d'un monticule de blocs de démolition, avec une dépression en son centre correspondant à l'espace interne de l'église. En outre, étant donné qu'il est peu probable que l'édifice en ruine ait servi de carrière en raison des difficultés d'accès, on doit envisager que l'église soit recouverte et comblée par sa propre démolition, et que par conséquent les vestiges soit particulièrement bien conservés.

30 La micro-topographie, le nettoyage des arases de maçonneries, et un petit sondage ont révélé une imposante citerne d'environ 11,50 x 5,20 m (dim. int.), soit de près de $60 \mathrm{~m}^{2}$. La citerne est quasiment au contact de l'abside et disposée selon un axe nord-ouest-sud-est en fonction de la proche falaise. Les murs est et nord mesurent seulement $0,80 \mathrm{~m}$ de largeur, alors que l'épaisseur du mur côté falaise est de 1,40 m. Le petit sondage de 0,85 x 
0,70 m ouvert dans l'angle sud-ouest de la structure, a révélé que les parements sont enduits de deux couches de mortier hydraulique (fig. 24).

Fig. 24 - Îlot de Lukovac, sondage dans l'angle de la citerne bordant la falaise.

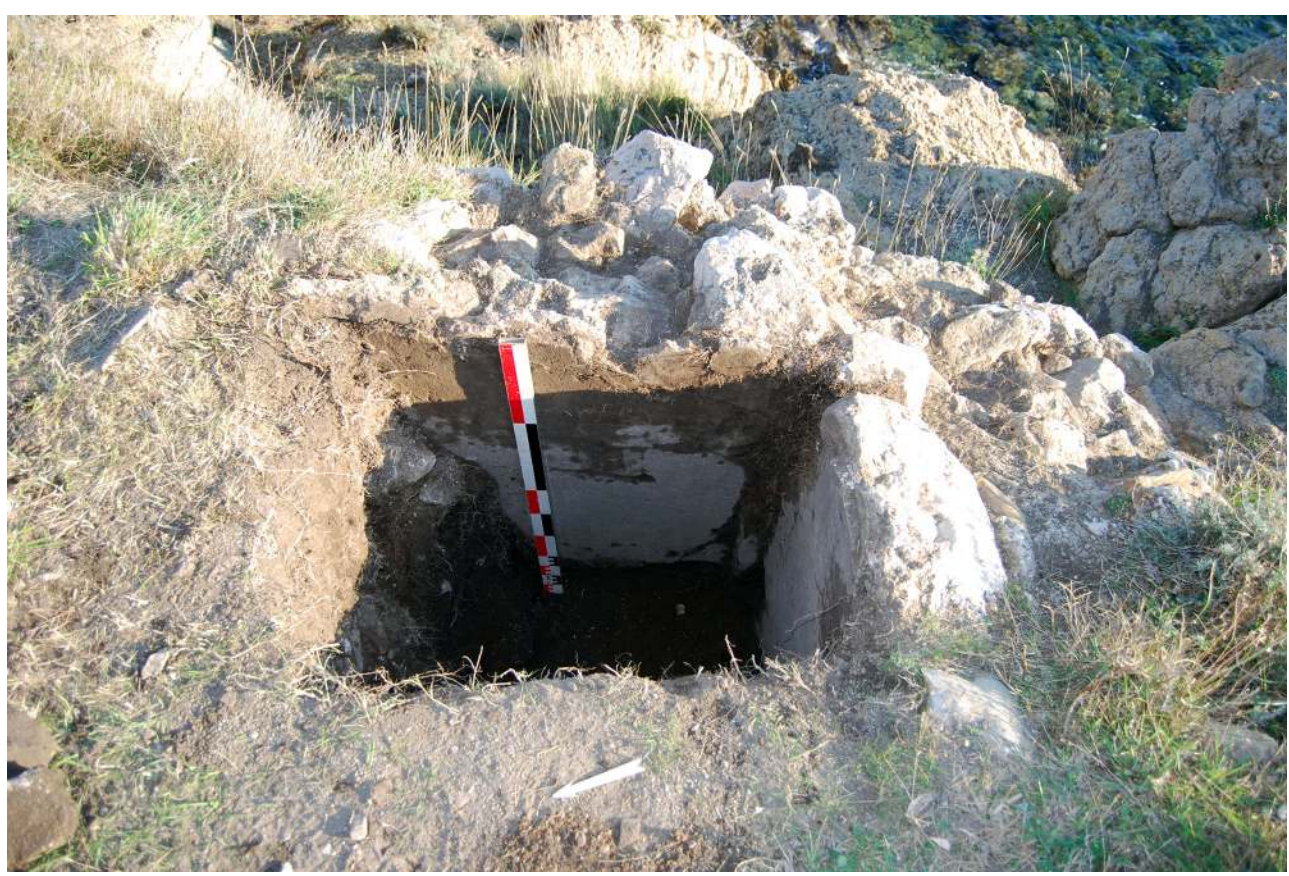

S. Bully, 2014.

Poursuivi jusqu'à 1,40 m de profondeur, le sondage n'a pas atteint le fond de la citerne. Son comblement stratifié est riche en mobilier céramique de l'Antiquité tardive, en débris d'amphores, en restes de faune et en charbons de bois. La citerne devait être alimentée par l'eau de pluie recueillie des toitures de l'église et d'autres constructions qui se développait parallèlement à l'est. Ces bâtiments, totalement enfouis, sont particulièrement bien visibles, sous la forme de rectangles de couleurs plus claires sur le MNT photogrammétrique (fig. 25). 
Fig. 25 - îlot de Lukovac, MNT photogrammétrique de l'îlot par photos drone et plan de l'église du $\mathrm{Vle}^{\mathrm{e}} \mathrm{s}$.

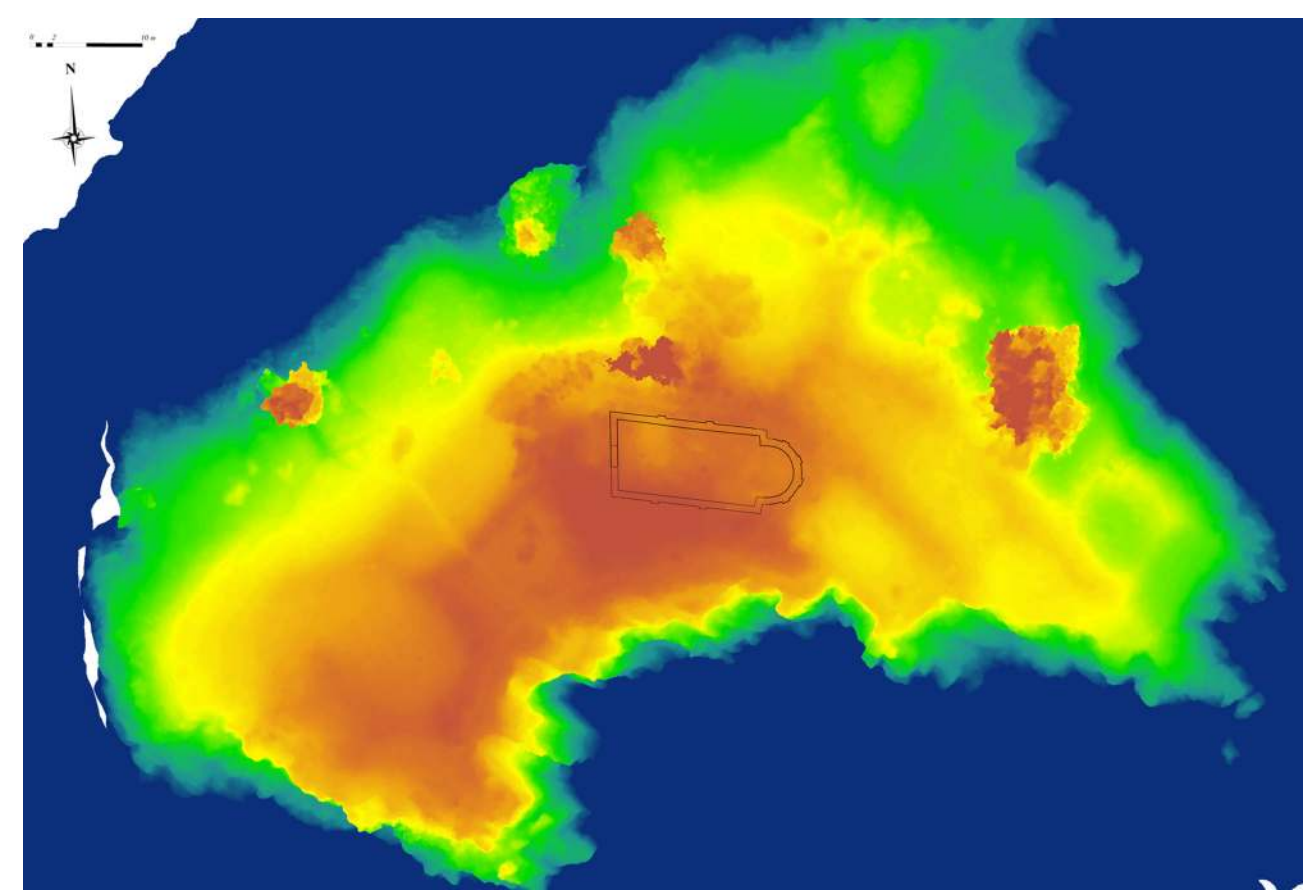

Société Kaducej, 2014

Les constructions enfouies, orientées nord-est-sud-ouest, sont bordées à l'est par une seconde ligne de bâtiments toujours perceptibles à travers la micro-topographie, mais également par des vestiges de murs et de sols de mortier. L'extrémité nord-est de l'îlot forme un éperon sur lequel on observe également des vestiges de constructions. Des murs d'enceintes et/ou de terrasses, parfois renforcés de sorte de contreforts, ferment l'îlot du côté de la baie au nord. La moitié ouest de l'îlot paraît moins densément construite, mais la micro-topographie indique une fois encore la présence de vastes constructions - dont une possible structure circulaire - et des vestiges de maçonneries ont été localisés en rebord des falaises sud.

\section{Conclusion}

31 À l'issue de cette seconde campagne, l'îlot broussailleux et ignoré de Lukovac a révélé un potentiel archéologique conséquent. On ne reviendra pas sur la proposition de datation de l'église dans le $\mathrm{VI}^{\mathrm{e}} \mathrm{s}$., peut-être même dans sa deuxième moitié. En revanche, il est à nouveau vraisemblable qu'il s'agisse bien d'une abside polygonale, et le plan de l'église s'est enrichi d'une probable galerie latérale sud - même on ne doit pas exclure la présence d'autres annexes. Mais l'apport le plus significatif de la courte campagne et la mise en évidence d'un grand nombre de maçonneries révélant que l'îlot était densément loti. Dans leurs dispositions, telle qu'on peut les restituer dans les grands traits, plusieurs édifices au chevet de l'église semblent faire front face au large bras de mer séparant l'île de Rab du continent. Certains murs en rupture de pente au nord étaient probablement nécessités par des aménagements de terrasses, alors que d'autres pouvaient avoir une fonction défensive. 
L'une des découvertes les plus significatives est la citerne : ses dimensions conséquentes indiquent que l'on est en présence d'un complexe organisé, pour une population qui ne devait pas être négligeable rapportée à la surface restreinte de l'îlot (moins de $90 \mathrm{~m}$ dans ses plus grandes longueurs). Sur la base du petit sondage, il a tout lieu de penser que la fouille de la citerne, avec l'étude de son riche mobilier, serait à même de répondre aux deux principales interrogations concernant le complexe de Lukovac, à savoir la nature de son occupation et sa durée. Si l'hypothèse d'un monastère ne peut pas encore être écartée, le contexte dans lequel s'inscrit le site, et désormais son organisation topographique, évoquent de plus en plus fortement un fortin lié au limes maritime byzantin créé à partir de la fin des guerres gothiques. Replacé dans une lecture plus globale du paysage côtier, l'îlot de Lukovac apparaîtrait comme le pendant insulaire du fortin de Klis de la baie de Lukovo, et aurait pu verrouiller le principal accès - par la baie de Crnika - à la partie nord de l'île de Rab.

\section{BIBLIOGRAPHIE}

Bully 2014 = S. Bully, Un dispositif funéraire spécifique : les formae. État de la question et nouvelles découvertes, dans Hortus Artium Medievalium, 20/2, 2014, p. 480-488.

Bully - Čaušević-Bully 2011 = S. Bully et M. Čaušević-Bully, Le monachisme insulaire dans l'archipel du Kvarner (Croatie) entre le $V^{e}$ et le XIe siècle. Projet de recherches archéologiques, 2011-2014, dans Bulletin du centre d'études médiévales d'Auxerre (BUCEMA), 15, Auxerre, 2011, p. 335-350 http:// cem.revues.org/index12017.html

Carre - Kovačić - Tassaux 2014 = M.-B. Carre, V. Kovačić et F. Tassaux, L'Istrie et la mer : la côte du Parentin dans l'Antiquité, Bordeaux, 2011.

Čaušević-Bully 2014 = M. Čaušević-Bully, La ville de Fulfinum (île de Krk). Nouveau regard sur le sort d'une ville antique entre l'Antiquité tardive et le haut Moyen Âge, dans Hortus Artium Medievalium, 20, 2014, p. 157-169

Čaušević-Bully - Bully 2013 = M. Čaušević-Bully et S. Bully, Esquisse d'un paysage monastique insulaire dans le nord de l'Adriatique : l'archipel du Kvarner (Croatie), dans Hortus Artium Medievalium, 19, 2013, p. 167-182.

Čaušević-Bully - Bully 2014 = M. Čaušević-Bully et S. Bully, Kvarner (Croatie). Prospection-inventaire des sites ecclésiaux et monastiques : campagne 2013, dans Chronique des activités archéologiques de l'École française de Rome, 2014, http://cefr.revues.org/1059.

Morvillez 1993 = E. Morvillez, Formes et évolution des salles de réception des grandes demeures tardives du bassin méditerranéen occidental (IVe-VI siècles), Thèse Université de Paris-IV Sorbonne, 1993.

Morvillez 2007 = E. Morvillez, Le fonctionnement de l'audience dans les grandes demeures de l'Antiquité tardive (IV $V^{e} V^{e}$ siècles), dans J.-P. Caillet et M. Sot (éd.), L'audience : rituels et cadres spatiaux dans l'Antiquité et le haut Moyen Âge, Paris, 2007, p. 175-192.

Ripoll - Arce $2000=\mathrm{G}$. Ripoll et J. Arce, The transformation and end of Roman villae in the West (Fourth-seventh centuries) : problems and perspectives, dans G. P. Brogiolo, N. Gauthier et N. Christie 
(éd.), Towns and their territories between Late Antiquity and the Early Middle Ages, Leiden-BostonCologne, 2000 (TRW, 9), p. 63-114.

Sfameni 2006 = C. Sfameni, Ville residenziali nell'Italia Tardoantica, Bari, 2006.

Sodini 1995 = J.-P. Sodini, Habitat de l'Antiquité tardive, dans Topoi, 5, 1995, p. 151-218.

Tuković 2011 = T. Tuković, The late antique " palace » in Polače Bay (Mljet) - Tertrachic « Palace » ?, dans Hortus Artium Medievalium, 17, 2011, p. 211-233.

\section{NOTES}

1. Il s'agit des sites de Saint-Pierre sur l'îlot d'Ilovik, Martinšćica sur l'île de Cres, Saint-Jean sur l'îlot d'Oruda, L'îlot de Lukovac dans la baie de rnika sur l'île de Rab, Saint-Laurent de Krk sur l'île de Krk, Mirine d'Omišalj sur l'île de Krk ; Bully - Čaušević-Bully 2011, p. 335-350.

2. Le financement des recherches a été est assuré par le ministère de la Culture croate, l'École française de Rome, la fondation Caritas Veritatis, les communes d'Omišalj, de Mali Lošinj et de Lopar, envers lesquelles nous exprimons toute notre gratitude. Avec les auteurs de cet article, l'équipe archéologique était formée par Ivan Valent, Iva Marić, Lucija Dugorepec, Edina Balić, Jessy Crochat, Inès Pacat, Katarina Rizner, Mia Rizner, Josip Burmaz et Dinko Tresić Pavičić (société Kaducej, relevés topographiques), Miro Vuković (couverture photographique par drone). L'essentiel de la gestion et de la logistique de l'opération est géré par les structures aIPAK et APAHJ.

3. Pour plus de précisions et une présentation des premiers résultats : Čaušević-Bully - Bully 2013, p. 167-182; Čaušević-Bully - Bully 2014.

4. Cal AD 420 (Cal BP 1530), Echantillon Beta-359177.

5. Čaušević-Bully - Bully 2014.

6. En cours d'identification.

7. Čaušević-Bully 2014, p. 157-169.

8. Avec le mausolée à formae plus tardif d'Osor ; cf. Bully 2014, p. 480-488.

9. Par Mario Novak, anthropologue, post-doctorant à l'UCI de Dublin.

10. Sur la difficulté d'interprétation de ce type de structure de l'Antiquité tardive, on se reportera par exemple au cas des vestiges de Vrsar en Istrie : Carre - Kovačić - Tassaux 2014, p. 260-265.

11. Parmi l'abondante bibliographie sur l'architecture des villae durant l'Antiquité tardive, on retiendra surtout: Morvillez 1993; Sodini 1995; Ripoll - Arce 2000; Sfameni 2006, plus particulièrement p. 86-96; Morvillez 2007 ; Tuković 2011.

12. Pour une présentation du site, on se reportera à la chronique 2013, Čaušević-Bully - Bully 2014. 
INDEX

Mots-clés : Croatie, insularité, haut Moyen Âge, Antiquité tardive, archéologie, archéologie du bâti, monastère, église, mausolée, funéraire, villa, salle de réception, fortin, byzantin institutions École française de Rome, UMR 6298 ARTeHIS (Dijon-Auxerre)

Index géographique : Croatie, Mirine, Martinšćica

\section{AUTEURS}

\section{MORANA ČAUŠEVIĆ-BULLY}

École française de Rome - morana.causevic[at]gmail.com

\section{SÉBASTIEN BULLY}

CNRS, UMR 6298 ArTeHiS - sebastien.bully[at]club-internet.fr 